Manuscript

\title{
Interface Control of Atomic Layer Deposited Oxide Coatings by Filtered Cathodic Arc Deposited Sublayers for Improved Corrosion Protection
}

\author{
Emma Härkönen $^{\mathrm{a}^{*}}$, Sanna Tervakangas ${ }^{\mathrm{b}}$, Jukka Kolehmainen $^{\mathrm{b}}$, Belén Díaz $^{\mathrm{c}}$, \\ Jolanta Ś wiatowska ${ }^{\mathrm{c}}$, Vincent Maurice ${ }^{\mathrm{c}}$, Antoine Seyeux ${ }^{\mathrm{c}}$, Philippe Marcus ${ }^{\mathrm{c}}$, Martin Fenker ${ }^{\mathrm{d}}$, \\ Lajos Tothe ${ }^{\mathrm{e}}$ György Radnoczi ${ }^{\mathrm{e}}$ and Mikko Ritala ${ }^{\mathrm{a}}$ \\ ${ }^{a}$ Laboratory of Inorganic Chemistry, University of Helsinki, P.O. Box 55, FIN-00014 \\ Helsinki, Finland \\ *emailemma.harkonen@helsinki.fi, tel.: +3589 19150215, fax: +358919150198 \\ ${ }^{\mathrm{b}}$ DIARC-Technology Inc., Espoo, Finland \\ ${ }^{\mathrm{c}}$ Laboratoire de Physico-Chimie des Surfaces, CNRS (UMR 7075) - Chimie ParisTech \\ (ENSCP), F-75005 Paris, France \\ ${ }^{\mathrm{d}}$ FEM Research Institute, Precious Metals and Metals Chemistry, D-73525 Schwäbisch \\ Gmünd, Germany \\ ${ }^{\mathrm{e}}$ Research Centre for Natural Sciences HAS, (MTA TKK), Budapest, Hungary.
}

\begin{abstract}
Sublayers grown with filtered cathodic arc deposition (FCAD) were added under atomic layer deposited (ALD) oxide coatings for interface control and improved corrosion protection of low alloy steel. The FCAD sublayer was either Ta:O or Cr:O-Ta:O nanolaminate, and the ALD layer was $\mathrm{Al}_{2} \mathrm{O}_{3}-\mathrm{Ta}_{2} \mathrm{O}_{5}$ nanolaminate, $\mathrm{Al}_{\mathrm{x}} \mathrm{Ta}_{\mathrm{y}} \mathrm{O}_{\mathrm{z}}$ mixture or $\mathrm{Al}_{\mathrm{x}} \mathrm{Ta}_{\mathrm{y}} \mathrm{O}_{\mathrm{z}}$ graded mixture. The total thicknesses of the FCAD/ALD duplex coatings were between 65-120 nm. Thorough analysis of the coatings was conducted to gain insight into the influence of the FCAD sublayer on the overall coating performance. Similar characteristics as with single FCAD and ALD coatings on steel were found in the morphology and composition of the duplex coatings. However, the FCAD process allowed better control of the interface with the steel by reducing the native oxide and preventing its regrowth during the initial stages of the ALD process. Residual hydrocarbon impurities were buried in the interface between the FCAD layer and steel. This enabled growth of ALD layers with improved electrochemical sealing properties, inhibiting the development of localized corrosion by pitting during immersion in acidic $\mathrm{NaCl}$ and enhancing durability in neutral salt spray testing.
\end{abstract}

Keywords: Atomic Layer Deposition; Filtered Cathodic Arc Deposition; Corrosion; Coating; Interfaces; Low alloy steel 
Manuscript

\section{Introduction}

Corrosion protection of engineering metals and alloys with atomic layer deposited (ALD) oxide coatings has gained increasing attention during the last years. Protective layers have been deposited on stainless steel [1-6], steel [7-13], aluminium alloys [7], magnesium alloys [14], magnesium-lithium alloys [15], copper [16,17] and silver [18]. Because ALD is based on alternating precursor pulses separated by inert gas purging, film growth occurs only on surfaces $[19,20]$. This leads to high conformality and uniformity even on challenging surface morphologies. Therefore ALD grown protective oxide layers offer significant advantages over ceramic coatings deposited on e.g. steel by many other methods [21-27]. Morphological heterogeneities, which pose a problem for physical vapour deposition (PVD) [22,23], do not influence the quality of the thin film and even complicated 3D objects can be coated conformally with ALD. Moreover, because complete burial of surface heterogeneities is not necessary, the ALD coatings can be considerably thinner than PVD coatings. Postdeposition annealing treatments, which are usually necessary with solution deposition techniques like sol-gel and can lead to crack formation [25], are not needed in ALD. Also intrinsic defect formation during the coating process, which is typical for instance for plasma electrolytic oxidation (PEO) [27], is not an issue for ALD. Thus very low pinhole and other defect densities can be accomplished with ALD. Furthermore, combining two or more materials into nanolaminates or mixtures allows easy modification of the composition and architecture of the coatings for the best combination of properties.

The ALD thin film materials that have been considered as protective coatings on steel are $\mathrm{Al}_{2} \mathrm{O}_{3}, \mathrm{TiO}_{2}$ and $\mathrm{Ta}_{2} \mathrm{O}_{5}$ [1-13]. The best sealing properties in electrochemical measurements were achieved with $\mathrm{Al}_{2} \mathrm{O}_{3}$ [1,4,7-9]. With $50 \mathrm{~nm}$ thin films deposited at $250{ }^{\circ} \mathrm{C}$ a three orders of magnitude decrease in passive current density of a stainless steel was obtained [4]. Similarly, on a low alloy steel a $50 \mathrm{~nm} \mathrm{Al}_{2} \mathrm{O}_{3}$ coating deposited at $160{ }^{\circ} \mathrm{C}$ decreased the corrosion current density by two orders of magnitude [8]. More moderate sealing properties were observed with the $\mathrm{TiO}_{2}$ and $\mathrm{Ta}_{2} \mathrm{O}_{5}$ coatings [1-6,10-12]. Unfortunately, $\mathrm{Al}_{2} \mathrm{O}_{3}$ was observed to dissolve from a steel surface at a rate of $7 \pm 1 \mathrm{~nm}$ per hour even in neutral $\mathrm{NaCl}$ solutions [9]. The dissolution was attributed to cathodic reduction of dissolved oxygen at the bottom of 
pinholes resulting in a local increase of $\mathrm{pH}$. The stability of the coatings could be improved by combining the insulating properties of $\mathrm{Al}_{2} \mathrm{O}_{3}$ with the chemical stability of $\mathrm{TiO}_{2}$ or $\mathrm{Ta}_{2} \mathrm{O}_{5}[1,3-6,10,12]$. The best long-term corrosion protection properties were achieved with $\mathrm{Al}_{2} \mathrm{O}_{3}-\mathrm{TiO}_{2}$ nanolaminate, $\mathrm{Al}_{2} \mathrm{O}_{3}-\mathrm{Ta}_{2} \mathrm{O}_{5}$ nanolaminate and $\mathrm{Al}_{\mathrm{x}} \mathrm{Ta}_{\mathrm{y}} \mathrm{O}_{\mathrm{z}}$ mixture coatings. The $\mathrm{Al}_{\mathrm{x}} \mathrm{Ta}_{\mathrm{y}} \mathrm{O}_{\mathrm{z}}$ mixture coatings were observed to have almost the same electrochemical properties as $\mathrm{Al}_{2} \mathrm{O}_{3}$, but also the stability of $\mathrm{Ta}_{2} \mathrm{O}_{5}$ [12].

The ALD film growth begins with chemical reactions between the precursors and the substrate surface $[19,20]$. Therefore the chemical species on the surface have an effect on the quality of the film deposited on top: a lack of appropriate surface species for the film growth can induce nucleation delays and poor adhesion, impurities and loose particles can induce defect formation, and hydrocarbon impurities can lead to poor adhesion and sealing properties [13,28,29]. The compositionally and morphologically heterogeneous industrial metal alloys do not offer the best starting surfaces for ALD film growth. Impurities and loose particles are hard to avoid and often the surfaces contain some type of a hydrocarbon layer. It has been observed that coatings deposited with thermal ALD on steel substrates that have been cleaned only by degreasing in organic solvents have problems with adhesion [7,13]. Pre-treatment with $\mathrm{H}_{2}$-Ar plasma was found to have a beneficial effect on the coating-steel interface, and thus both adhesion and electrochemical barrier properties of the coatings could be improved [13]. However, even better properties can be expected when the ALD films are grown on clean, compositionally homogeneous surfaces with appropriate starting points for the film growth.

Filtered cathodic arc deposition (FCAD) is a PVD technique [30,31]. It is based on a low-voltage, high-current plasma discharge between two metallic electrodes. The plasma discharge brings forth an arc current composed of high-energy ions and electrons. A part of the ion flux is directed to a substrate after magnetically filtering away macroparticles formed in the plasma. The film deposition occurs through bombardment of the substrate with the high-energy ion flux. This leads to films with excellent adhesion, high density and hardness. The process can also involve an in situ pre-cleaning step that removes impurities like hydrocarbons and oxide layers from the substrate surface. FCAD coatings are widely used as hard protective coatings for 
Manuscript

reducing mechanical wear $[32,33]$. The characteristics of FCAD make it an ideal candidate to be combined with ALD for resolving the challenging aspects of the solely ALD-based protective coatings on metallic substrates.

In this study, we have combined the advantageous properties of FCAD with ALD films by preparing thin ( $\leq 120 \mathrm{~nm}$ ) FCAD/ALD duplex coatings for corrosion protection of steel. Careful attention was given to the effect of the FCAD sublayers on the morphology, composition, electrochemical properties, stability and long-term corrosion protection properties of the ALD coatings. Two FCAD sublayers, $10 \mathrm{~nm}$ Ta:O and $50 \mathrm{~nm} \mathrm{Cr:O-Ta:O} \mathrm{nanolaminate,} \mathrm{were} \mathrm{employed} \mathrm{[11,34].} \mathrm{The} \mathrm{top} \mathrm{ALD}$ layers were $50 \mathrm{~nm} \mathrm{Al}_{2} \mathrm{O}_{3}-\mathrm{Ta}_{2} \mathrm{O}_{5}$ nanolaminate and $\mathrm{Al}_{\mathrm{x}} \mathrm{Ta}_{\mathrm{y}} \mathrm{O}_{\mathrm{z}}$ mixtures with either homogenous or graded composition as selected based on previously published results $[10,12]$. 


\section{Experimental}

Low alloy steel (AISI 52100, DIN 100Cr6) hardened (805 HV hardness) and tempered (at $180^{\circ} \mathrm{C}$ ) was used as a substrate material. The composition of the steel was (in wt.\%) C (0.95-1.1), Cr (1.5), Ni (max. 0.30), Mn (0.25-0.45), Cu (max. 0.30), Si (0.15-0.35), P (max. 0.030), S (max. 0.025) and Fe (balance). The substrate surfaces were lapped in a water based diamond suspension $(6 \mu \mathrm{m})$ and brushed.

The FCAD coating process was carried out in a DIARC-Technology Inc. coating equipment. The deposition sequence was the same as presented in previous publications [11,34]. Before coating the samples were wiped with acetone, ultrasonicated in isopropanol for $5 \mathrm{~min}$, rinsed with isopropanol and blow-dried with compressed air. Then they were etched in situ in the FCAD chamber with $350 \mathrm{eV}$ Ar ions at $0.5 \mathrm{~mA} \mathrm{~cm}^{-2}$ current density for $30 \mathrm{~min}$. The metal oxide coatings, Ta:O and $\mathrm{Cr}$ :O, were produced from $\mathrm{Cr}$ and $\mathrm{Ta}$ plasma in presence of low partial pressure of oxygen. The deposition temperature was below $100{ }^{\circ} \mathrm{C}$.

Prior to ALD the samples were once more wiped with acetone, ultrasonicated in acetone and isopropanol for $5 \mathrm{~min}$, rinsed with ethanol and blow-dried with compressed air. Further purification of the surface was done by $\mathrm{H}_{2}$-Ar plasma at 160 ${ }^{\circ} \mathrm{C}$ in a Beneq TFS-200 ALD reactor according to methodology detailed in a previous publication [13]. The plasma was generated by a capacitively coupled $13.56 \mathrm{MHz} \mathrm{rf}$ power source. The reactor was operated in a remote plasma configuration, i.e. the plasma was separated from the substrates by a metal grid. The plasma gases Ar (>99.999\%) and $\mathrm{H}_{2}(>99.999 \%)$ were purified on site with Aeronex Gatekeeper and Entergris Gatekeeper purifiers. The gas flows were maintained constant at 130 and 15 sccm for Ar and $\mathrm{H}_{2}$. The pre-treatment was conducted by ALD type pulsing to avoid excessive temperature increase during the plasma treatment. The plasma was turned on for $5 \mathrm{~s}$ and off for $10 \mathrm{~s}$. The cycle was repeated 360 times to reach the desired 30 min pre-treatment time. The plasma power was $170 \mathrm{~W}$. The pre-treatments were conducted ex situ, i.e. after the pre-treatment the reactor was cooled to $100{ }^{\circ} \mathrm{C}$, opened to normal laboratory air and the samples were moved into the reactor used for the ALD deposition as fast as possible. The approximate air exposure time was 2-3 min. 
ALD coatings were prepared in a Picosun SUNALE R-150 reactor at $160{ }^{\circ} \mathrm{C}$. The ALD process details were the same as in previous publications $[10,12]$. The precursors were trimethyl aluminium $\left(\mathrm{Al}\left(\mathrm{CH}_{3}\right)_{3}, \mathrm{TMA}\right.$, Chemtura AXION® PA 1300), tantalum pentaethoxide $\left(\mathrm{Ta}\left(\mathrm{OC}_{2} \mathrm{H}_{5}\right)_{5}, \mathrm{SAFC}\right.$ Hitech $\left.{ }^{\mathrm{TM}}\right)$ and ultrapure water $\left(\mathrm{H}_{2} \mathrm{O}\right.$, resistivity $\left.>18 \mathrm{M} \Omega \mathrm{cm}\right)$. TMA and $\mathrm{H}_{2} \mathrm{O}$ were evaporated at room temperature and $\mathrm{Ta}\left(\mathrm{OC}_{2} \mathrm{H}_{5}\right)_{5}$ at $140{ }^{\circ} \mathrm{C}$. The pulse lengths were $0.1 \mathrm{~s}$ in $\mathrm{Al}_{2} \mathrm{O}_{3}$ and $0.4 \mathrm{~s}$ in $\mathrm{Ta}_{2} \mathrm{O}_{5}$ deposition sequence. The purge was always $5 \mathrm{~s}$. The growth rate of $\mathrm{Al}_{2} \mathrm{O}_{3}$ was 0.09 $\mathrm{nm}$ cycle ${ }^{-1}$ and $\mathrm{Ta}_{2} \mathrm{O}_{5} 0.04 \mathrm{~nm}$ cycle ${ }^{-1}$. The number of cycles was chosen so that the nominal $50 \mathrm{~nm}$ coating thickness was reached.

The coatings prepared, their coding and nominal thicknesses are presented in Table 1. The FCAD coatings are coded by a letter F and the ALD coatings by a letter A. Thereafter the FCAD and ALD coatings are numbered from 1 to 3. Duplex coatings bear the coding of both the FCAD and the ALD layers.

The FCAD and ALD coating thicknesses were measured from silicon samples coated simultaneously with the steel substrates. The measurements were conducted with a Dektak 3ST profilometer and x-ray reflectance (XRR, Bruker AXS D8 Advance diffractometer) for the FCAD and ALD thin films, respectively. The XRR curves were modelled with Leptos 7.05.

The pristine morphology of the coatings was studied with field emission scanning electron microscopy (FESEM, Hitachi S-4800) and transmission electron microscopy (TEM, Philips CM20). FESEM imaging was used to study the surface morphology of the steel before and after coating with FCAD and ALD. TEM was used for cross sectional imaging of the samples. Prior to TEM analysis, the samples were thinned by standard mechanical grinding and ion bombardment techniques: the samples were cut, embedded into a Ti-holder, mechanically ground and polished, and finally milled with $10 \mathrm{keV} \mathrm{Ar}{ }^{+}$ions. The final step of the ion milling was carried out with $3 \mathrm{keV}$ to minimize the damage to the thinned samples.

The composition of the coatings and the coating-substrate interface was studied with time-of-flight secondary ion mass spectrometry (ToF-SIMS). A ToF-SIMS 5 spectrometer (IonToF) was employed. The measurements were done with a pulsed 25 
$\mathrm{keV} \mathrm{Bi}^{+}$primary ion source delivering $0.8 \mathrm{pA}$ of analysis current over a $100 \times 100 \mu \mathrm{m}^{2}$ area. The depth profiling was done by sputtering with a $2 \mathrm{keV} \mathrm{Cs}^{+}$beam giving a target current of $82 \mathrm{nA}$ over a $400 \times 400 \mu \mathrm{m}^{2}$ area. Negative ion profiles were used as they are more sensitive to fragments from oxide matrixes. The operation pressure was $10^{-9}$ mbar. Ion-Spec software was used for the data acquisition and post-processing.

Polarization (linear sweep voltammetry, LSV) measurements were used for evaluating the electrochemical properties of the coatings. The measurements were conducted with an AUTOLAB PGSTAT30 potentiostat/galvanostat at room temperature in a $0.2 \mathrm{M} \mathrm{NaCl}$ solution (Analar Normpur analytical reagent VWR ${ }^{\circledR}$ BDH Prolabo $\left.{ }^{\circledR}\right)$ at $\mathrm{pH}$ 7. The electrolyte solution was bubbled with Ar for $30 \mathrm{~min}$ prior to starting and throughout the measurements. A three-electrode system with platinum as the counter electrode and standard calomel electrode (SCE) as the reference was used. The electrochemical measurements were always started with 30 min open circuit potential (OCP) measurement to ensure stability of the system. Polarization was measured from $-0.9 \mathrm{~V}$ up until the anodic current density exceeded $10 \mu \mathrm{A} \mathrm{cm}^{-2}$ with a scan rate of $1 \mathrm{mV} \mathrm{s}^{-1}$. The exposed sample area was limited to 0.44 $\mathrm{cm}^{2}$ with a Viton o-ring. Corrosion current densities and corrosion potentials were obtained by Tafel analysis $[35,36]$.

The stability of the coatings was evaluated by immersion in a $0.2 \mathrm{M} \mathrm{NaCl}$ solution at pH $2(0.01 \mathrm{M} \mathrm{HCl})\left(\mathrm{NaCl}\right.$ and $\mathrm{HCl} 37 \%$ Analar Normpur analytical reagent VWR ${ }^{\circledR}$ BDH Prolabo $\left.{ }^{\circledR}\right)$. The total immersion time was $6 \mathrm{~h}$. During immersion electrochemical impedance spectroscopy (EIS) measurements were conducted at regular intervals with the AUTOLAB PGSTAT30 potentiostat/galvanostat. The EIS measurements were done at OCP with the exciting signal amplitude set to $10 \mathrm{mV}$. The frequency range was from $10^{-2}$ to $10^{5} \mathrm{~Hz}$. The experimental impedance spectra were modeled with the ZSimp-Win software based on the minimization of the $\chi^{2}$ function, defined as the sum of the squares of the differences between the measured and the calculated data. After the stability testing the ToF-SIMS depth profile analysis was repeated to gain insight into the compositional changes of the samples. The depth profiles were measured as detailed above. 
Manuscript

Corrosion durability was studied with a neutral salts spray (NSS) test according to the standard DIN 50021 (ISO 9227) with the exception that the samples were removed from the chamber at regular intervals, rinsed with deionised water and photographed. During NSS the temperature, $\mathrm{NaCl}$ concentration and $\mathrm{pH}$ were kept constant at $35 \pm 2$ ${ }^{\circ} \mathrm{C}, 50 \pm 5 \mathrm{~g} / 1$ and 6.5-7.2, respectively. The extent of corrosion in per cents after 2,4 , 24 and $48 \mathrm{~h}$ of exposure was quantified according to the Renault standard D17 1058J. A grid consisting of $4 \times 4 \mathrm{~mm}$ squares was placed on the sample and the number of squares containing corrosion spots was considered against the total number of squares. The whole square was considered corroded if even one corrosion spot could be found in it. At the edges of the circular samples only tiles filled with over $50 \%$ by the sample were considered. Rust grading for the samples was then given according to percentages in standard DIN 51802 (Table 2). 
Manuscript

\section{Results and Discussion}

\subsection{Coating Morphology and Composition}

In the FESEM images the bare substrate surface appeared heterogeneous (Figure 1a). Scratches, holes and particles could be observed. The $50 \mathrm{~nm}$ ALD mixture coating (A2) or nanolaminate (not shown) alone covered the surface conformally slightly blurring the scratches (Figure 1b), as was observed previously [10,12]. The $10 \mathrm{~nm}$ FCAD Ta:O coating (F1) followed the surface of the substrate closely (Figure 1c), but also made some of the scratches and holes more pronounced. A smoother surface was observed with the $50 \mathrm{~nm}$ FCAD Cr:O-Ta:O nanolaminate (F3) coating (Figure 1d) that buried some surface irregularities. The ALD top layers in the duplex coatings smoothened the surface further by conformal coverage (Figure 1e and f). No defects could be observed in any of the studied coatings (Figure 1).

The FCAD and ALD layers were clearly visible and distinguishable in the cross sectional TEM images (Figure 2). The interfaces were sharp and both layers followed the surface conformally. The duplex coatings appeared to be well adhered to the substrate and the layers to each other, confirming previous results for single coatings $[7,12,34]$. All the FCAD and ALD layers also seemed to be amorphous, as expected [37]. No pinholes or other defects could be observed with the local TEM cross sectional analysis. The FCAD layers were slightly thicker than their nominal values suggested. The "10 nm Ta:O" layer (F1) was $15 \mathrm{~nm}$ thick and the "50 nm Cr:OTa:O nanolaminate" layer (F3) $\sim 70 \mathrm{~nm}$. The ALD mixture layer was close to the nominal $50 \mathrm{~nm}$ thickness.

ToF-SIMS depth profiles of the FCAD Ta:O combined with the ALD nanolaminate (F1-A1), mixture (F1-A2) and graded mixture (F1-A3) layers are presented in Figure 3. The depth profiles had similar general features as single FCAD and ALD coatings on steel $[8-12,34]$. The coating and interface regions could be easily distinguished. The interface starting point was determined from the start of an increase of $\mathrm{Fe}^{-}$and $\mathrm{Cr}^{-}$ ion profiles. Different from the single ALD coatings and similar to the single FCAD coatings on steel, no peak in the $\mathrm{FeO}_{2}^{-}, \mathrm{CrO}_{2}^{-}, \mathrm{Fe}^{-}$and $\mathrm{Cr}^{-}$ion profiles could be observed at the coating-substrate interface $[8-12,34]$. The Ar ion etch process prior to FCAD appeared to have completely etched away any native oxide on the steel 
Manuscript

surface, as discussed previously [11,34]. The FCAD coating also suppressed formation of a new interface layer by oxidation of steel during exposure air and in the initial stages of the ALD process. Native oxide suppression and inhibition of oxide regrowth were confirmed by the TEM data (Figure 2) that did not show the approximately $10 \mathrm{~nm}$ thick interface layer observed between the single ALD coatings and substrate [8-13]. Instead $\mathrm{TaC}^{-}$and $\mathrm{C}^{-}$ToF-SIMS signals appeared to peak at the FCAD coating-steel interface. This can be attributed to a formation of a $\mathrm{Ta} / \mathrm{Ta}-\mathrm{C}$ interlayer due to a reaction of the carbonaceous impurities remaining on the substrate with the first tantalum ions arriving in the beginning of the FCAD process $[11,34]$.

The coating region could be further divided into separate ALD and FCAD layers (Figure 3). The end of the ALD top layer and start of the FCAD sublayer was taken as the point where $\mathrm{TaO}_{2}{ }^{-}$signal started to increase or $\mathrm{AlO}_{2}{ }^{-}$signal started to decrease near the interface with the substrate. The sputtering times for reaching the FCAD layer differed for the three samples. Rather than being an indication of different thicknesses of the ALD layers, this was likely due to matrix effects encountered when measuring depth profiles of films with different compositions [38]. The FCAD layers and their interfaces to steel seemed to remain unaffected by the ALD process on top of them, and only low $\mathrm{OH}^{-}, \mathrm{Cl}^{-}$and $\mathrm{C}^{-}$impurity signals could be seen (Figure 3). No signal from the substrate species could be seen in the entire duplex coating region indicating that the coatings were pinhole free at least in the resolution of the ToFSIMS equipment used.

In the depth profile of the FCAD Ta:O and ALD nanolaminate (F1-A1) duplex coating the different layers of the ALD nanolaminate could be easily distinguished (Figure 3a). Clear peaking of $\mathrm{Al}^{-}, \mathrm{AlO}_{2}^{-}, \mathrm{Ta}^{-}$and $\mathrm{TaO}_{2}^{-}$ion intensities could be observed in the corresponding $\mathrm{Al}_{2} \mathrm{O}_{3}$ and $\mathrm{Ta}_{2} \mathrm{O}_{5}$ layers. The peaks of the different layers appeared to overlap. Rather than implicating that the layers were mixed, this was probably due to the roughness of the substrate $[4,10]$. The $\mathrm{C}^{-}$impurity signal peaked with the $\mathrm{Ta}_{2} \mathrm{O}_{5}$ layers, and the $\mathrm{OH}^{-}$signal at the interfaces between the $\mathrm{Al}_{2} \mathrm{O}_{3}$ and $\mathrm{Ta}_{2} \mathrm{O}_{5}$ layers. This was observed also previously with the single ALD nanolaminates on steel, and mirrors the higher amount of impurities in the ALD $\mathrm{Ta}_{2} \mathrm{O}_{5}$ compared to $\mathrm{Al}_{2} \mathrm{O}_{3}$ [10]. Peaking of $\mathrm{Cl}^{-}$could be seen in the $\mathrm{Ta}_{2} \mathrm{O}_{5}$ layers. In the $\mathrm{ALD} \mathrm{Al}_{2} \mathrm{O}_{3}$ coatings on steel the chlorine contamination has been assigned to a 
Manuscript

$\leq 0.01$ wt. \% dimethylaluminium chloride (DMACl) impurity content of the aluminium precursor TMA [12]. The exact origin of the chlorine contamination in the ALD $\mathrm{Ta}_{2} \mathrm{O}_{5}$ coatings on steel has not been cleared [12]. However, the total $\mathrm{Cl}^{-}$ contamination in both $\mathrm{Al}_{2} \mathrm{O}_{3}$ and $\mathrm{Ta}_{2} \mathrm{O}_{5}$ has been shown to be below the detection limit 0.5 at. $\%$ of x-ray photoelectron spectroscopy (XPS) $[8,11]$.

The depth profile of the ALD top layer in the FCAD Ta:O and ALD mixture (F1-A2) duplex coating appeared very similar to a single ALD mixture coating on steel (Figure 3b) [12]. The $\mathrm{Al}^{-}, \mathrm{AlO}_{2}^{-}, \mathrm{Ta}^{-}$and $\mathrm{TaO}_{2}^{-}$signals were constant throughout the ALD layer thickness, showing homogeneous in-depth composition, and $\mathrm{C}^{-}, \mathrm{OH}^{-}$and $\mathrm{Cl}^{-}$ impurities were observed.

The depth profile of the FCAD Ta:O and ALD graded mixture (F1-A3) duplex coating on steel is presented in Figure 3c. In the ALD top layer a fast decrease of $\mathrm{Ta}^{-}$ and $\mathrm{TaO}_{2}{ }^{-}$could be observed indicating that the composition changed monotonously through the coating from $\mathrm{Ta}_{2} \mathrm{O}_{5}$ to $\mathrm{Al}_{2} \mathrm{O}_{3}$ as designed. The $\mathrm{Al}^{-}$and $\mathrm{AlO}_{2}^{-}$signals changed also along the depth profile, but the change was not as fast as for the $\mathrm{Ta}_{2} \mathrm{O}_{5}$ species. The differences in the slopes were most probably due to matrix effects [38]. The $\mathrm{C}^{-}$impurity signal decreased with the $\mathrm{Ta}_{2} \mathrm{O}_{5}$ species along the coating thickness confirming the higher carbon contamination of ALD $\mathrm{Ta}_{2} \mathrm{O}_{5}$ compared to $\mathrm{Al}_{2} \mathrm{O}_{3}$ [10]. The $\mathrm{OH}^{-}$and $\mathrm{Cl}^{-}$impurity signals were approximately constant throughout the thickness.

\subsection{Barrier properties of the coatings}

The i-E polarization curves of uncoated, single FCAD and duplex FCAD/ALD coated steel in $0.2 \mathrm{M} \mathrm{NaCl}$ solutions at $\mathrm{pH} 7$ are presented in Figure 4. The polarization curve of the uncoated steel indicated that the anodic reaction was activation controlled, and the cathodic reaction was under diffusion control near the corrosion potential and under activation control at the most negative potentials [35]. The active anodic behaviour was expected as the steel contains only low amounts of $\mathrm{Cr}$ (1.5 wt.\%). The diffusion controlled cathodic reaction was the reduction of dissolved oxygen, the concentration of which was very low in the Ar bubbled electrolyte solution. The activation controlled cathodic reaction was hydrogen reduction. The 
Manuscript

corrosion current density of the uncoated steel was determined by Tafel analysis $[36,37]$ to be $4.6 \times 10^{-7} \mathrm{Acm}^{-2}$ (Table 3 ).

The polarization curves of the single FCAD coated samples had similar characteristics as the uncoated steel (Figure 4a). With both coatings (F1 and F3) the anodic reaction appeared to have shifted towards positive potentials indicating some ennoblement of the steel-coating system. As discussed previously [11,34], and confirmed by the present ToF-SIMS data, it is likely that the removal of the native oxide present on the uncoated alloy by pre-etching in the FCAD process promotes corrosion resistance of the reactive uncoated surface. The thicker FCAD Cr:O-Ta:O nanolaminate (F3) coating had an additional benefit of significantly decreasing the access of oxygen to the steel surface and thus reducing the corrosion current density by two orders of magnitude compared to the uncoated steel (Table 3).

The FCAD/ALD duplex coatings all had better protective properties than the single FCAD coatings (Figure $4 \mathrm{~b}$ and $\mathrm{c}$ ). Similar behaviour as for the uncoated steel was observed for the duplex coatings. However, due to the extremely low current densities observed for most samples in the cathodic potential range, the reaction mechanisms could not be determined certainly. The current was at or below the detection limit of the equipment used for the measurements. The ALD mixture layers on the FCAD Ta:O and Cr:O-Ta:O nanolaminate layers (F1-A2 and F3-A2, respectively) appeared to slightly reduce the corrosion potential of the uncoated steel and to create a semipassive range in the anodic branch. A similar response was observed with ALD $\operatorname{Ta}_{2} \mathrm{O}_{5}$ and sufficiently $\mathrm{Ta}_{2} \mathrm{O}_{5}$-rich mixtures on steel $[11,12]$. The behaviour was assigned to a growth of an unusually chromium-rich, considering the steel composition, corrosion product layer at the steel-coating interface during exposure of the samples to air after plasma pre-treatment or in the beginning of the ALD film growth. This phenomenon was less apparent with the ALD mixture on the thicker FCAD Cr:O-Ta:O nanolaminate layer (F3-A2), which indicates that in the F1-A2 sample the thin FCAD Ta:O layer was not sealing sufficiently to prevent interface oxidation. This is supported by the high porosity of the single FCAD Ta:O coating presented below (Table 3). However, the FCAD/ALD mixture duplex coatings showed also slightly inferior polarization behaviour compared to single ALD mixture on steel [12]. The poorer sealing properties of the ALD mixtures on the FCAD sublayers may be due to 
a detrimental interaction of the tantalum precursor with the FCAD layers. In particular, the oxygen deficient FCAD Ta:O layers [11] may promote decomposition of $\mathrm{Ta}\left(\mathrm{OC}_{2} \mathrm{H}_{5}\right)_{5}$ leading to defects. Indeed, all the other FCAD/ALD duplex coatings (F1-A1, F1-A3, F3-A1 and F3-A3) where the ALD coating started with $\mathrm{Al}_{2} \mathrm{O}_{3}$ on the FCAD sublayer, had better sealing properties than the corresponding single ALD coatings [12]. The difference to the duplex coatings with the ALD mixture top layers might be the prevention of $\mathrm{Ta}\left(\mathrm{OC}_{2} \mathrm{H}_{5}\right)_{5}$ interacting with the oxygen deficient FCAD layers by the $\mathrm{ALD} \mathrm{Al}_{2} \mathrm{O}_{3}$ starting layer, or the more sealing nature of $\mathrm{ALD} \mathrm{Al}_{2} \mathrm{O}_{3}$ compared to $\mathrm{Ta}_{2} \mathrm{O}_{5}$ inhibiting more efficiently the oxidation of the steel surface through defects in the FCAD layer. In duplex coatings with ALD nanolaminate or graded mixture the only improvement obtained by the thicker FCAD sublayer appeared to be moving the anodic reaction to higher potentials and thus extending the low current density range to approximately $100 \mathrm{mV}$ higher potentials.

The corrosion current densities of the duplex coatings were determined by Tafel analysis on the anodic branch and fitting of a line on the cathodic branch $[12,39]$. The corrosion current densities were obtained from the intersection of the fitted lines. Compared to uncoated steel a decrease of more than three orders of magnitude in the corrosion current densities could be achieved with the best FCAD/ALD duplex coatings (Table 3 ).

To simplify the comparison of the coatings and their sealing properties, coating porosities $(P)$ were calculated from the polarization results. The porosities represent the surface fraction of the substrate exposed to the surrounding environment through defects. The analysis was made based on corrosion current densities according to a procedure adapted from Tato et al. [40] (Equation 1).

$$
P=\frac{i_{\text {corr }}}{i_{\text {corr }}^{0}} \times 100 \%
$$

where $i_{\text {corr }}{ }^{0}$ represents the corrosion current density of the bare substrate, and $i_{\text {corr }}$ the corrosion current density of the coated substrate under evaluation. 
The calculated porosities are presented in Table 3. The FCAD Ta:O coating (F1) had an unrealistically large porosity of $55 \%$ considering that the coating appeared continuous in FESEM and TEM (Figures 1 and 2). The evaluation of porosities based on corrosion current densities assumes that the coating is inert. However, FCAD Ta:O coatings have been observed to be significantly oxygen deficient [11,34] explaining the high porosity obtained for the continuous coating. Porosities of the same order of magnitude were detected also previously for thin $10 \mathrm{~nm}$ FCAD Ta:O coatings on steel [34]. The FCAD Cr:O-Ta:O nanolaminate (F3) had a significantly lower porosity of $1.1 \%$, owing to the higher thickness and possibly to the less oxygen deficient $\mathrm{Cr}: \mathrm{O}$ layers [34]. All the FCAD/ALD duplex coatings had lower porosities than the corresponding single FCAD coating. The ALD mixture on FCAD Ta:O (F1-A2) and Cr:O-Ta:O nanolaminate (F3-A2) coatings had porosities of 2.0 and $0.04 \%$. As already discussed above, this implies a less effective or similar sealing as was observed with single ALD mixture on steel (0.04\%) [12], possibly due to a detrimental reaction of the $\mathrm{Ta}\left(\mathrm{OC}_{2} \mathrm{H}_{5}\right)_{5}$ ALD precursor with the oxygen deficient FCAD Ta:O [11]. The other duplex coatings, ALD nanolaminate on FCAD Ta:O (F1A1) and Cr:O-Ta:O nanolaminate (F3-A1), and ALD graded mixture on FCAD Ta:O (F1-A3) and Cr:O-Ta:O nanolaminate (F3-A3), had porosities very close to each other $(0.06 \pm 0.02 \%)$. Significant improvement from the porosities of single ALD nanolaminate $(0.7 \%)$ and graded mixture $(0.2 \%)$ on steel [12] could be achieved indicating better sealing with the duplex coatings, however with a total thickness exceeding that of the single ALD counterparts. The thicker Cr:O-Ta:O nanolaminate sublayers (F3) appeared to offer little improvement compared to the thinner Ta:O sublayers (F1) under the ALD nanolaminate and graded mixture layers even though there was a significant difference between the porosities of the single FCAD layers. This implies that the Ta:O layer was sufficient in homogenizing the interface for good ALD growth, and that the sealing properties were mainly obtained from the ALD layers.

\subsection{Coating stability and performance during immersion in acidic $\mathrm{NaCl}$}

ToF-SIMS depth profiles of FCAD Ta:O and ALD duplex coatings on steel after a 6$\mathrm{h}$ immersion in $0.2 \mathrm{M} \mathrm{NaCl}$ solution at $\mathrm{pH} 2$ are presented in Figure 3. Stabilities of the single FCAD and $\mathrm{ALD} \mathrm{Al}_{2} \mathrm{O}_{3}$ and $\mathrm{Ta}_{2} \mathrm{O}_{5}$ coatings on steel in the same conditions have been studied $[9,11]$, and that of $\mathrm{Al}_{\mathrm{x}} \mathrm{Ta}_{\mathrm{y}} \mathrm{O}_{\mathrm{z}}$ mixture will be reported separately. 
FCAD Ta:O coatings were found to be stable throughout the immersion in $\mathrm{NaCl}$ at $\mathrm{pH} 2$ [11]. Immersion of the $\mathrm{ALD}_{2} \mathrm{O}_{2}$ in $0.2 \mathrm{M} \mathrm{NaCl}$ solution at $\mathrm{pH} 7$ showed clear dissolution of the coating: the sputtering time needed to reach the interface layer decreased linearly with the immersion time [9]. Chloride ions penetrated through the coating and accumulated at the interface. A simultaneous decrease of the hydroxide ion intensity suggested that the chloride ions replaced hydroxyl impurities in the coating. In contrast, single ALD $\mathrm{Ta}_{2} \mathrm{O}_{5}$ coatings were found stable in the $0.2 \mathrm{M} \mathrm{NaCl}$ solution at $\mathrm{pH} 7$ and $\mathrm{pH} 2$ [11]. However, similar penetration of chloride ions through the coating, as observed with $\mathrm{Al}_{2} \mathrm{O}_{3}$, was also observed with $\mathrm{Ta}_{2} \mathrm{O}_{5}$ coatings. With the single $\mathrm{Al}_{\mathrm{x}} \mathrm{Ta}_{\mathrm{y}} \mathrm{O}_{\mathrm{z}}$ mixtures on steel in $0.2 \mathrm{M} \mathrm{NaCl}$ solution at $\mathrm{pH} 2$ no coating dissolution occurred, but penetration of chloride ions through the coating was indicated by some accumulation at the interface.

The depth profiles of the FCAD/ALD duplex coatings are nearly identical before and after immersion (Figure 3). The sputtering times needed to reach the FCAD and interface regions were the same indicating that no general dissolution of the coatings occurred. The same compositional features and the same intensities could be observed. The only difference was an increase of the $\mathrm{Cl}^{-}$intensity in the outermost parts of the ALD $\mathrm{Ta}_{2} \mathrm{O}_{5}$ layers (Figure 5). This behaviour could be seen in the ALD nanolaminate (F1-A1) and graded mixture (F1-A3) topped coatings. In the ALD mixture topped coating the $\mathrm{Cl}^{-}$intensity was the same before and after immersion. It is well known that ALD $\mathrm{Ta}_{2} \mathrm{O}_{5}$ is more porous than ALD $\mathrm{Al}_{2} \mathrm{O}_{3}[4,10-12,41]$, thus enabling $\mathrm{Cl}^{-}$penetration only in the outermost $\mathrm{Ta}_{2} \mathrm{O}_{5}$ layers of the nanolaminate and graded mixture as observed in the present study. The decrease of the porosity when reaching an $\mathrm{Al}_{2} \mathrm{O}_{3}$ layer (nanolaminate) or a sufficiently $\mathrm{Al}_{2} \mathrm{O}_{3}$ rich layer (graded mixture) hindered further penetration.

The general appearances of the EIS Bode plots during immersion in $0.2 \mathrm{M} \mathrm{NaCl}$ solution at pH 2 were similar for all the duplex FCAD Ta:O and ALD coated samples (Figure 6). At the high frequencies the spectra were constant throughout the immersion. At the middle frequencies the impedances appeared constant, but the phase angles were slightly modified at the frequencies between $10^{-1}$ and $10^{1} \mathrm{~Hz}$. This is different from what was observed for single $\mathrm{ALD} \mathrm{Al}_{2} \mathrm{O}_{3}$ coatings in neutral $\mathrm{NaCl}$ solutions where modifications appeared in the whole frequency range [9]. With $\mathrm{Al}_{2} \mathrm{O}_{3}$ 
coatings the modifications were assigned to variation of the coating thickness and to redox reactions occurring on the substrate surface at the bottom of pinholes. Another phenomenon must be occurring on the duplex samples as no variation of the coating thickness was observed with ToF-SIMS and the differences in phase angle modification imply a process with a different time constant. On steel coated with single ALD $\mathrm{Ta}_{2} \mathrm{O}_{5}$ layers and on anodized aluminium alloys and aluminium alloys passivized in $\mathrm{CeCl}_{3}$ solutions, changes in the frequency range from $10^{-1}$ to $10^{1} \mathrm{~Hz}$ have been assigned to pitting corrosion $[11,42,43]$. At the low frequencies a decrease of global impedance was observed, indicating a decrease of protective properties of the coatings during the immersion. The only clear difference between the shapes of the spectra for the three FCAD/ALD duplex coatings was the greater modification of the ALD laminate topped sample after two hours of immersion compared to the other two coatings. For the ALD mixture and graded mixture the decrease of global impedance was smaller and approximately constant throughout the immersion.

The Nyquist plots gave some further information on the corrosion phenomena on the sample surfaces (Figure 7). In addition to the high frequency capacitive semicircle, mostly responsible for the phenomena observed in the Bode plots, an inductive loop could also be seen at the low frequencies. During immersion this inductive loop appeared to start changing into a capacitive semicircle. This was also observed with ALD $\mathrm{Ta}_{2} \mathrm{O}_{5}$ coatings on steel in acidic $\mathrm{NaCl}$ [11]. In literature the inductive to capacitive transformation is usually assigned to increasing corrosion product accumulation on iron or steel surfaces in acidic solutions $[44,45]$. With the ALD $\mathrm{Ta}_{2} \mathrm{O}_{5}$ coated steel the accumulation of $\mathrm{FeO}_{2}{ }^{-}$and $\mathrm{CrO}_{2}^{-}$at the bottom of pinholes at the coating-substrate interface was also observed with ToF-SIMS [11]. However, no such increase could be observed with ToF-SIMS for the duplex coatings (Figure 3). It is probable that the FCAD layer suppressed the oxidation of the interface so much that it could not be detected with ToF-SIMS.

The equivalent circuit used for the data modelling is presented in Figure 8. It is a modification of the circuit previously discussed by Bonnel et al. [46] and Díaz et al. $[9,11]$. The coated surface is characterized by a coating capacitance, $C_{\text {coat }}$. The uncoated surface fraction, i.e. steel surface exposed through coating pinholes, is represented by charge transfer resistance, $R_{c t}$, in parallel with a series of resistance of 
pitting corrosion, $R_{p i t}$ and double layer capacitance, $C_{d l}$. $R_{p i t}$ represents defects that evolve during the immersion while $R_{c t}$ represents the continuously corroding steel surface. The solution resistance, $R_{e}$, is in series with all these components. This circuit was chosen mainly on the base of previous EIS results on immersion of single FCAD or ALD coated steel in $\mathrm{NaCl}$ where two time constants were very clearly distinguishable from each other $[9,11]$. The inductive loop observed in the Nyquist plots in the beginning of immersion (Figure 7) was not considered in the fitting as further discussion on it is beyond the aim of the present paper. All the capacitances are presented by constant phase elements (CPE), with which the un-ideal capacitive behaviour caused by surface heterogeneity can be considered [47]. The impedance of a CPE is represented by Equation 2 [48].

$$
Z_{C P E}=\frac{1}{Q(j w)^{n}}
$$

where $Q$ and $n$ can be obtained directly from the fitting. The value of $\mathrm{Q}$ is independent of frequency, and the factor $n$ represents the CPE power, which is related in Nyquist plots to the angle of depression of the semicircle beneath the $\mathrm{x}$-axis by (1$n) \times 90^{\circ}$. The real capacitances can be evaluated using the Brug approach (Equation 3) [49].

$$
C=Q^{1 / n}\left(\frac{1}{R_{c t}}+\frac{1}{R_{e}}\right)^{\frac{n-1}{n}}
$$

where the contribution of $R_{c t}$ is negligible due to $R_{c t}>>R_{c}$. The fitted values after 0.5 , 1,3 and 6 hours of immersion are shown in Table 4. The capacitances calculated using Equation 3 are presented instead of CPEs.

The corrosion rate can be considered based on the charge transfer resistances, $R_{c t}$ (Table 4). All duplex coatings had larger $R_{c t}$ values than the single FCAD or ALD coatings and significantly higher values than the uncoated steel $[9,11,35]$. This indicates that the duplex coatings were more efficient in inhibiting the corrosion of steel than the single FCAD or ALD layers. In the beginning of immersion the duplex coatings could be arranged in order based on their protective properties: F1-A1 > F1- 
A3 $>$ F1-A2. In the end of immersion the order had changed to F1-A3 $>$ F1-A1 $>$ F1A2. The end-of-immersion order is in line with that of the polarization results (Table 3). Since the polarization measurements are more destructive than EIS, the better correspondence of the polarization results with the EIS results after 6 hours rather than at the beginning of immersion can be accounted for.

The pitting resistances, $R_{p i t}$, correspond to local modifications in the pinholes exposing the steel surface, i.e. pitting corrosion $[42,43]$. The $R_{p i t}$ values of the duplex coatings both at the beginning and end of immersion could be arranged in order F1A3 $>$ F1-A1 > F1-A2 (Table 4), which corresponds with the polarization results and charge transfer resistances at the end of immersion. The $R_{p i t}$ values of all the duplex coatings were very close to each other at the end of immersion indicating that pitting corrosion was similar.

Both resistances $R_{c t}$ and $R_{p i t}$ were observed to be higher and to decrease less during the immersion for the FCAD/ALD duplex-coated samples than for the single ALD mixture that will be reported separately. However, in the $R_{p i t}$ values the difference was larger: a decrease of approximately one order of magnitude was observed during immersion of the duplex-coated samples, while the decrease was more than two orders of magnitude for the single ALD mixture. This indicates that the FCAD sublayer significantly inhibited the pitting process. It was observed above (Figure 3) that the FCAD layers suppressed the formation of an interfacial oxide layer and buried the hydrocarbon contamination, and it is known that ALD film growth is sensitive to the substrate surface state $[13,28,29]$. Thus the improved resistance to pitting was probably due to improved initial ALD growth on a more homogeneous and less contaminated surface.

The coating capacitances, $C_{\text {coat }}$, remained constant throughout the immersion (Table 4). As previously discussed $[9,11,51]$, this is an indication that the coatings were stable and no general dissolution occurred confirming the ToF-SIMS data. Additionally the CPE powers were very close to unity showing that the coating surfaces were homogenous and smooth [47]. The capacitances of the duplex coatings were quite close to each other. The values increased in order F1-A3 $<$ F1-A1 $<$ F1- 
A2. If a parallel plate capacitor structure is assumed the capacitances, $C$, can be evaluated from Equation 4 [52].

$$
C=\frac{\varepsilon_{0} \varepsilon_{r} A}{d}
$$

where $\varepsilon_{0}$ represents vacuum dielectric constant $\left(8.85 \times 10^{-14} \mathrm{~F} \mathrm{~cm}^{-1}\right), \varepsilon_{r}$ dielectric constant of the coating material, $A$ area and $d$ thickness. Amorphous $\mathrm{ALD} \mathrm{Al}_{2} \mathrm{O}_{3}$ and $\mathrm{Ta}_{2} \mathrm{O}_{5}$ deposited at $250{ }^{\circ} \mathrm{C}$ are known to have approximate dielectric constants of 8 and $21[54,55]$. The content of $\mathrm{Ta}_{2} \mathrm{O}_{5}$ is also smaller in the graded mixture than in the mixture ALD coating [12]. Therefore if the area and thickness of the coatings were the same, the capacitance values corresponded well with the general composition of the coatings.

The double layer capacitances, $C_{d l}$, of all the coatings increased slightly during the immersion (Table 4). If a parallel plate capacitor is again assumed (Equation 4), the result implies an increase of surface area of steel exposed to solution. Because the $R_{p i t}$ is connected in series with the $C_{d l}$ in the equivalent circuit, and the $R_{p i t}$ values decreased during immersion, an increase of pit density and/or size was implied. The CPE powers for the double layer capacitances were between 0.8 and 0.6 with no clear trends detected. CPE powers between 0.8 and 0.6 are usually taken to represent general corrosion [45]. The small fluctuation probably implied some changes in the exposed surface morphology at the bottom of the coating pinholes.

\subsection{Corrosion protection properties}

The NSS durability results on single FCAD and duplex FCAD/ALD coated steel are presented in Figure 9 and Table 5. The single FCAD coated samples were completely covered by corrosion spots and had a rust grade of 5 after two hours of testing. After four hours the number of corrosion spots appeared almost the same, but their size had increased. In an earlier publication it was observed that on steel coated with single ALD nanolaminate, mixture and graded mixture the first corrosion spots appeared after two, four and two hours, respectively [12]. However, the extent of corrosion was quite low still after 24 hours of testing with all the single ALD coatings. 
Manuscript

All the samples with the FCAD/ALD duplex coatings had better corrosion durability than the samples with single FCAD or ALD coatings (Figure 9 and Table 5). On samples with the FCAD Ta:O combined with the ALD nanolaminate, mixture or graded mixture the first corrosion spots appeared after 24 hours of testing. Even after 48 hours the samples had only scattered corrosion spots and large areas on the sample surfaces remained corrosion-free. The best protective properties were achieved with the ALD nanolaminate top coating (F1-A1). On samples with the FCAD Cr:O-Ta:O nanolaminate under the ALD nanolaminate or mixture the corrosion started already after two hours of testing. However, the extent of corrosion was extremely low. With the naked eye only a few corrosion spots could be observed on samples coated with both types of ALD coatings. After 48 hours of testing the samples appeared similar to the ALD coatings combined with the thinner FCAD Ta:O sublayer, and the sample surfaces were still mostly corrosion free. Overall similar results were achieved with all the duplex coatings after 48 hours of immersion. These results support the conclusion made from the porosities that the thicker FCAD sublayer did not offer significant improvement to the duplex coatings. The main benefits of the FCAD sublayers were obtained already with the thin Ta:O layers.

Significant improvement to the single FCAD or ALD coating durability was achieved with the duplex coatings (Figure 9) [12]. However, the first corrosion spots could be observed after 24 hours of NSS testing even in the best cases (Figure 10 and Table 5). Many industrial applications require $>100 \mathrm{~h}$ NSS durability rendering even the FCAD/ALD duplex coatings unsuitable. Thus the long-term durability of the coating systems should be further developed. Additionally, the ultra thin $(\leq 120 \mathrm{~nm})$ ceramic layers cannot withstand mechanical wear. Sealing of thick PVD coatings on steel by ALD has been previously suggested $[55,56,57]$. Another possibility would be to first seal a surface with ALD or FCAD/ALD duplex coating, and thereafter grow a thick PVD layer on top. 
Manuscript

\section{Conclusions}

In this work the beneficial effect of adding thin $(\leq 70 \mathrm{~nm})$ FCAD sublayer to ALD oxide nanocoatings for improved corrosion protection of low alloy steel has been demonstrated. Combined FESEM, TEM, ToF-SIMS, LSV and EIS analysis was conducted, and coating durability was assessed with NSS testing. The coatings were found to be conformal and uniform, and the adhesion between the FCAD and ALD layers and substrate appeared sufficient. The different layers in the coatings could be easily distinguished both by cross-sectional and depth profile analysis. The bulk regions of the FCAD and ALD layers were similar in composition to the corresponding single coatings on steel. The FCAD process was observed to efficiently remove and suppress the formation of a layer of iron/chromium oxide at the coatingsubstrate interface and to bury residual carbonaceous impurities of the substrate surface in the FCAD-substrate interface. As a result, both the electrochemical sealing properties and NSS durability of the duplex coatings were improved compared to single FCAD and ALD coatings. Immersion tests of the duplex-coated steel in acidic $\mathrm{NaCl}$ solutions showed that the initial charge transfer and pitting resistances were higher than for the single layer coated samples and the decrease of the resistances during the immersion was slower. Additionally, the duplex coatings were stable and compositionally almost unaffected by the immersion.

The beneficial influence of the FCAD sublayer appeared to arise from a better control of the interface. The homogenous FCAD oxide without significant carbonaceous contamination enabled a more ideal start for the ALD film growth. The coatings thus had fewer weak points, which are likely sites for initiation and development of localized corrosion by pitting in aggressive environments. Hence the FCAD sublayer inhibited the nucleation and/or growth of pits at the least protected sites, thus slowing down the development of localized corrosion and improving the protection properties of the coatings. 
Manuscript

\section{Acknowledgements}

The research leading to these results has received funding from the European Community's Seventh Framework Program (FP7/2007- 2013) under grant agreement n CP-FP 213996-1. Academy of Finland (Finnish Centre of Excellence in Atomic Layer Deposition) is also thanked for support. Region Ile-de-France is acknowledged for partial support for the ToF-SIMS equipment. 
Manuscript

\section{References}

[1] R. Matero, M. Ritala, M. Leskelä, T. Salo, J. Aromaa, O. Forsén, J. Phys. IV France 9 (1999) Pr8-493-Pr8-499.

[2] C.X. Shan, X. Hou, K.-L. Choy, Surf. Coat. Tech. 202 (2008) 2399-2402.

[3] E. Marin, A. Lanzutti, F. Andreatta, M. Lekka, L. Guzman, L. Fedrizzi, Corr. Rev. 29 (2011) 191-208.

[4] B. Díaz, J. Światowska, V. Maurice, A. Seyeux, B. Normand, E. Härkönen, M. Ritala, P. Marcus, Electrochim. Acta 56 (2011) 10516-10523.

[5] E. Marin, A. Lanzutti, L. Guzman, L. Fedrizzi, J. Coat. Technol. Res. 8 (2011) 655-659.

[6] E. Marin, L. Guzman, A. Lanzutti, W. Ensinger, L. Fedrizzi, Thin Solid Films 522 (2012) 283-288.

[7] S.E. Potts, L. Schmalz, M. Fenker, B. Díaz, J. Światowska, V. Maurice, A. Seyeux, P. Marcus, G. Radnóczi, L. Tóth, W.M.M. Kessels, J. Electrochem. Soc. 158 (2011) C132-C138.

[8] B. Díaz, E. Härkönen, J. Światowska, V. Maurice, A. Seyeux, P. Marcus, M. Ritala, Corr. Sci. 53 (2011) 2168-2175.

[9] B. Díaz, E. Härkönen, J. Światowska, V. Maurice, A. Seyeux, M. Ritala, P. Marcus, Electrochim. Acta 56 (2011) 9609-9618.

[10] E. Härkönen, B. Díaz, J. Światowska, V. Maurice, A. Seyeux, M. Vehkamäki, T. Sajavaara, M. Fenker, P. Marcus, M. Ritala, J. Electrochem. Soc. 158 (2011) C369-C378.

[11] B. Díaz, J. Światowska, V. Maurice, A. Seyeux, E. Härkönen, M. Ritala, S. Tervakangas, J. Kolehmainen, P. Marcus, Electrochim. Acta 90 (2013) 232245 .

[12] E. Härkönen, B. Díaz, J. Światowska, V. Maurice, A. Seyeux, M. Fenker, L. Tóth, G. Radnóczi, P. Marcus, M. Ritala, Chem. Vapor Dep. 19 (2013) 194203.

[13] E. Härkönen, S. Potts, W.M.M. Kessels, B. Díaz, A. Seyeux, J. Światowska, V. Maurice, P. Marcus, G. Radnóczi, L. Tóth, M. Kariniemi, J. Niinistö, M. Ritala, Thin Solid Films 534 (2013) 384-393.

[14] E. Marin, A. Lanzutti, L. Guzman, L. Fedrizzi, J. Coat. Technol. Res. 9 (2012) 347-355. 
Manuscript

[15] P.C. Wang, Y.T. Shih, M.C. Lin, H.C. Lin, M.J. Chen, K.M. Lin, Thin Solid Films 518 (2010) 7501-7504.

[16] A.I. Abdulagatov, Y. Yan, J.R. Cooper, Y. Zhang, Z.M. Gibbs, A.S. Cavanagh, R.G. Yang, Y.C. Lee, S.M. George, ACS Appl. Mater. Interfaces 3 (2011) 4593-4601.

[17] M.L. Chang, T.C. Cheng, M.C. Lin, H.C. Lin, M.J. Chen, Appl. Surf. Sci. 258 (2012) 10128-10134.

[18] L. Paussa, L. Guzman, E. Marin, N. Isomäki, L. Fedrizzi, Surf. Coat. Technol. 206 (2011) 976-980.

[19] M. Ritala, M. Leskelä, Atomic layer deposition, in H.S. Nalwa (Ed.), Handbook of Thin Film Materials, Academic Press, San Diego, 2001, pp. 103158 .

[20] M. Ritala, J. Niinistö, Atomic layer deposition, in A.C. Jones, M.L. Hitchman (Eds.), Chemical Vapour Deposition: Precursors, Processes and Applications, The Royal Society of Chemistry, Cambridge, 2009, pp. 158-206

[21] V.K.W. Grips, V.E. Selvi, H.C. Barshilia, K.S. Rajam, Electrochim. Acta 51 (2006) 3461-3468.

[22] Y. Dianran, H. Jining, W. Jianjun, Q. Wanqi, M. Jing, Surf. Coat. Technol. 89 (1997) 191-195.

[23] M. Cekada, P. Panjan, D. Kek-Merl, M. Panjan, G. Kapun, Vacuum 82 (2008) 252-256.

[24] D. Wang, G.P. Bierwagen, Prog. Org. Coat. 64 (2009) 327-338.

[25] G. Ruhi, O.P. Modi, A.S.K. Sinha, I.B. Singh, Corr. Sci. 50 (2008) 639-649.

[26] W.-C. Gu, G.-H. Lv, H. Chen, G.-L. Chen, W.-R. Feng, G.-L. Zhang, S.-Z. Yang, J. Alloys Comp. 430 (2007) 308-312.

[27] W. Gu, D. Shen, Y. Wang, G. Chen, W. Feng, G. Zhang, S. Fan, C. Liu, S. Yang, Appl. Surf. Sci. 252 (2006) 2927-2932.

[28] Y. Zhang, D. Seghete, A. Abdulagatov, Z. Gibbs, A. Cavanagh, R. Yang, S. George, Y.-C. Lee, Surf. Coat. Tech. 205 (2011) 3334-3339.

[29] M.D. Groner, J.W. Elam, F.H. Fabrequette, S.M. George, Thin Solid Films 413 (2002) 186-197.

[30] I.G. Brown, Annu. Rev. Mater. Sci. 28 (1998) 243-269.

[31] B. K. Tay, Z. W. Zhao, D. H. C. Chua, Mater. Sci. Eng. R52 (2006) 1-48

[32] A. Anders, Vacuum 67 (2002) 673-686. 
Manuscript

[33] S. PalDey, S.C. Deevi, Mater. Sci. Eng. A342 (2003) 58-79.

[34] B. Díaz, J. Światowska, V. Maurice, M. Pisarek, A. Seyeux, S. Zanna, S. Tervakangas, J. Kolehmainen, P. Marcus, Surf. Coat. Technol. 206 (2012) 3903-3910.

[35] L.J. Korb, Metals Handbook, 9th ed., vol.13, ASM International, Ohio, 1987.

[36] M. Stern, A.L. Geary, J. Electrochem. Soc. 104 (1957) 56-63.

[37] V. Miikkulainen, M. Leskelä, M. Ritala, R. Puurunen, Appl. Phys. Rev. 113 (2013) 021301.

[38] A.M. Belu, D.J. Graham, D.G. Castner, Biomaterials 24 (2003) 3635-3653

[39] R. Hausbrand, B. Bolando-Escudero, A. Dhont, J. Wielant, Corr. Sci. 61 (2012) 28-34.

[40] W. Tato, D. Landolt, J. Electrochem. Soc. 145 (1998) 4173-4181.

[41] K. Kukli, J. Ihanus, M. Ritala, M. Leskelä, J. Electrochem. Soc. 144 (1997) 300-306.

[42] F. Mansfeld, S. Lin, S. Kim, H. Shih, J. Electrochem. Soc. 137 (1990) 78-82.

[43] H. Herrera-Hernandez, J.R. Vargas-Garcia, J.M. Hallen-Lopez, F. Mansfeld, Mater. Corr. 58 (2007) 825-832.

[44] I. Ebelboin, M. Keddam, J.C. Lestrade, Faraday Discuss. Chem. Soc. 56 (1973) 264-275.

[45] P. Li, T.C. Tan, J.Y. Lee, Corr. Sci. 38 (1996) 1935-1955.

[46] A. Bonnel, J. Babosi, C. Deslouis, M. Duprat, M. Keddam, B. Tribollet, J. Electrochem. Soc. 130 (1983) 753-761.

[47] J.-B. Jorcin, M.E. Orazem, N. Pébère, B. Tribollet, Electrochim. Acta 51 (2006) 1473-1479.

[48] E. Barsukov, J.R. Macdonald, Impedance Spectroscopy: Theory, Experiment and Applications, 2nd Edition, John Wiley \& Sons Inc., Hoboken, New Jersey, 2000.

[49] G.J. Brug, A.L.G. van den Eeden, M. Sluyters-Rebach, J.H. Sluyters, J. Electroanal. Chem. 176 (1984) 275-295.

[50] I. Ebelboin, M. Keddam, H. Takenouti, J. Appl. Electrochem. 2 (1972) 71-79.

[51] C. Corfias, N. Pébère, C. Lacabanne, Corr. Sci. 41 (1999) 1539-1555.

[52] W.D. Callister, Materials Science and Engineering: An Introduction, 7th Edition, John Wiley \& Sons, Inc., United States of America, 2007. 
Manuscript

[53] R. Matero, A. Rahtu, M. Ritala, M. Leskelä, T. Sajavaara, Thin Solid Films $368(2000) 1-7$.

[54] K. Kukli, M. Ritala, M. Leskelä, J. Electrochem. Soc. 142 (1995) 1670-1675.

[55] C.X. Shan, X. Hou, K.-L. Choy, P. Choquet, Surf. Coat. Technol. 202 (2008) 2147-2151.

[56] E. Marin, L. Guzman, A. Lanzutti, L. Fedrizzi, M. Saikkonen, Electrochem. Comm. 11 (2009) 2060-2063.

[57] P.C. Wang, T.C. Cheng, H.C. Lin, M.J. Chen, K.M. Lin, M.T. Yeh, Appl. Surf. Sci. 270 (2013) 452-456 
Manuscript

Tables and Figures

Table 1. Coding and nominal thicknesses of studied coatings on steel.

\begin{tabular}{|c|c|c|}
\hline Code & FCAD layer & ALD layer \\
\hline F1 & $10 \mathrm{~nm} \mathrm{Ta:O}$ & - \\
\hline F2 & $50 \mathrm{~nm} \mathrm{Ta}: \mathrm{O}$ & - \\
\hline $\mathbf{F 3}$ & $\begin{array}{c}2 \times[10+10] \text { Cr:O-Ta:O nanolaminate } \\
+10 \mathrm{~nm} \mathrm{Cr:O}\end{array}$ & - \\
\hline F1-A1 & $10 \mathrm{~nm} \mathrm{Ta:O}$ & $\begin{array}{c}2 \times[12.5+12.5] \mathrm{nm} \\
\mathrm{Al}_{2} \mathrm{O}_{3}-\mathrm{Ta}_{2} \mathrm{O}_{5} \text { nanolaminate }\end{array}$ \\
\hline F1-A2 & $10 \mathrm{~nm}$ Ta:O & $50 \mathrm{~nm} \mathrm{Al}_{\mathrm{x}} \mathrm{Ta}_{\mathrm{y}} \mathrm{O}_{\mathrm{z}}$ mixture \\
\hline F1-A3 & $10 \mathrm{~nm} \mathrm{Ta}: \mathrm{O}$ & $50 \mathrm{~nm} \mathrm{Al}_{\mathrm{x}} \mathrm{Ta}_{\mathrm{y}} \mathrm{O}_{\mathrm{z}}$ graded mixture \\
\hline F3-A1 & $\begin{array}{c}2 \times[10+10] \text { nm Cr:O-Ta:O nanolaminate } \\
+10 \mathrm{~nm} \mathrm{Cr}: \mathrm{O} \\
\end{array}$ & $\begin{array}{c}2 \times[12.5+12.5] \mathrm{nm} \\
\mathrm{Al}_{2} \mathrm{O}_{3}-\mathrm{Ta}_{2} \mathrm{O}_{5} \text { nanolaminate }\end{array}$ \\
\hline F3-A2 & $\begin{array}{c}2 \times[10+10] \mathrm{nm} \text { Cr:O-Ta:O nanolaminate } \\
+10 \mathrm{~nm} \mathrm{Cr}: \mathrm{O}\end{array}$ & $50 \mathrm{~nm} \mathrm{Al}_{\mathrm{x}} \mathrm{Ta}_{\mathrm{y}} \mathrm{O}_{\mathrm{z}}$ mixture \\
\hline F3-A3 & $\begin{array}{c}2 \times[10+10] \text { nm Cr:O-Ta:O nanolaminate } \\
+10 \mathrm{~nm} \mathrm{Cr}: \mathrm{O}\end{array}$ & $50 \mathrm{~nm} \mathrm{Al}_{\mathrm{x}} \mathrm{Ta}_{\mathrm{y}} \mathrm{O}_{\mathrm{z}}$ graded mixture \\
\hline
\end{tabular}


Manuscript

Table 2. Definition of rust grades according to standard DIN 51802.

\begin{tabular}{|c|c|c|}
\hline $\begin{array}{c}\text { Rust } \\
\text { grade }\end{array}$ & Description of the rust figure & $\begin{array}{c}\text { Area of } \\
\text { corrosion / \% }\end{array}$ \\
\hline 0 & No corrosion & 0 \\
\hline 1 & Maximum 3 corrosion spots covering less than $1 \mathrm{~mm}^{2}$ & Not defined \\
\hline 2 & Slight corrosion & $<1$ \\
\hline 3 & Moderate corrosion & $1-5$ \\
\hline 4 & Heavy corrosion & $5-10$ \\
\hline 5 & Very heavy corrosion & $>10$ \\
\hline
\end{tabular}


Manuscript

Table 3. Tafel analysis results from polarization measurements on bare, single FCAD and duplex FCAD/ALD coated steel.

\begin{tabular}{|c|c|c|}
\hline Sample & $\begin{array}{c}\text { Corrosion current } \\
\text { density } \\
/ \times \mathbf{1 0}^{-\mathbf{9}} \mathbf{A c m}^{-\mathbf{2}}\end{array}$ & $\begin{array}{c}\text { Porosity } \\
/ \mathbf{\%}\end{array}$ \\
\hline Bare steel & 460 & 100 \\
\hline F1 & 250 & 55 \\
\hline F3 & 5.3 & 1.1 \\
\hline F1-A1 & 0.35 & 0.08 \\
\hline F1-A2 & 9.4 & 2.0 \\
\hline F1-A3 & 0.23 & 0.05 \\
\hline F3-A1 & 0.21 & 0.05 \\
\hline F3-A2 & 0.19 & 0.04 \\
\hline F3-A3 & 0.32 & 0.07 \\
\hline
\end{tabular}


Manuscript

Table 4. EIS fitting results on duplex FCAD/ALD coated steel during immersion in

$0.2 \mathrm{M} \mathrm{NaCl}$ solution at $\mathrm{pH} 2$.

\begin{tabular}{|c|c|c|c|c|c|c|c|c|}
\hline & time & $\mathbf{R}_{\mathbf{e}} / \mathbf{\Omega}$ & $\mathbf{C}_{\text {coat }} / \mathbf{F}$ & $\mathbf{n}_{\mathbf{1}}$ & $\mathbf{R}_{\mathbf{c t}} / \mathbf{\Omega}$ & $\mathbf{C}_{\mathbf{d l}} / \mathbf{F}$ & $\mathbf{R}_{\text {pit }} / \mathbf{\Omega}$ & $\mathbf{n}_{\mathbf{2}}$ \\
\hline \multirow{4}{*}{ F1-A1 } & $30 \mathrm{~min}$ & 68 & $1.4 \mathrm{e}-7$ & 1.0 & $2.3 \mathrm{e} 7$ & $1.5 \mathrm{e}-8$ & $2.0 \mathrm{e} 6$ & 0.80 \\
\cline { 2 - 9 } & $1 \mathrm{~h}$ & 67 & $1.4 \mathrm{e}-7$ & 1.0 & $1.5 \mathrm{e} 7$ & $2.4 \mathrm{e}-8$ & $7.1 \mathrm{e} 5$ & 0.74 \\
\cline { 2 - 9 } & $3 \mathrm{~h}$ & 65 & $1.3 \mathrm{e}-7$ & 1.0 & $2.9 \mathrm{e} 6$ & $1.2 \mathrm{e}-7$ & $6.0 \mathrm{e} 5$ & 0.72 \\
\cline { 2 - 9 } & $6 \mathrm{~h}$ & 65 & $1.3 \mathrm{e}-7$ & 1.0 & $1.4 \mathrm{e} 6$ & $2.9 \mathrm{e}-7$ & $2.6 \mathrm{e} 5$ & 0.70 \\
\hline \multirow{5}{*}{ F1-A2 } & $30 \mathrm{~min}$ & 71 & $1.6 \mathrm{e}-7$ & 0.98 & $3.4 \mathrm{e} 6$ & $6.3 \mathrm{e}-8$ & $8.7 \mathrm{e} 5$ & 0.64 \\
\cline { 2 - 9 } & $1 \mathrm{~h}$ & 71 & $1.6 \mathrm{e}-7$ & 0.98 & $2.1 \mathrm{e} 6$ & $6.2 \mathrm{e}-8$ & $6.5 \mathrm{e} 5$ & 0.60 \\
\cline { 2 - 9 } & $3 \mathrm{~h}$ & 70 & $1.6 \mathrm{e}-7$ & 0.98 & $1.4 \mathrm{e} 6$ & $1.3 \mathrm{e}-7$ & $2.9 \mathrm{e} 5$ & 0.60 \\
\cline { 2 - 9 } & $6 \mathrm{~h}$ & 70 & $1.6 \mathrm{e}-7$ & 0.98 & $9.3 \mathrm{e} 5$ & $1.9 \mathrm{e}-7$ & $2.3 \mathrm{e} 5$ & 0.73 \\
\hline \multirow{5}{*}{ F1-A3 } & $30 \mathrm{~min}$ & 69 & $1.2 \mathrm{e}-7$ & 0.98 & $7.8 \mathrm{e} 6$ & $4.9 \mathrm{e}-8$ & $7.6 \mathrm{e} 6$ & 0.71 \\
\cline { 2 - 9 } & $1 \mathrm{~h}$ & 68 & $1.2 \mathrm{e}-7$ & 0.98 & $5.4 \mathrm{e} 6$ & $7.9 \mathrm{e}-8$ & $1.4 \mathrm{e} 6$ & 0.76 \\
\cline { 2 - 9 } & $3 \mathrm{~h}$ & 65 & $1.2 \mathrm{e}-7$ & 0.98 & $2.8 \mathrm{e} 6$ & $9.2 \mathrm{e}-8$ & $2.8 \mathrm{e} 5$ & 0.73 \\
\cline { 2 - 9 } & $6 \mathrm{~h}$ & 64 & $1.2 \mathrm{e}-7$ & 0.98 & $2 \mathrm{e} 6$ & $1.5 \mathrm{e}-7$ & $2.9 \mathrm{e} 5$ & 0.79 \\
\hline
\end{tabular}


Manuscript

Table 5. Rust grades of single FCAD and duplex FCAD/ALD coated steel during NSS testing.

\begin{tabular}{|c|c|c|c|c|}
\hline \multirow{2}{*}{ Code } & \multicolumn{4}{|c|}{ NSS } \\
\cline { 2 - 5 } & After 2h & After 4h & After 24h & After 48 h \\
\hline F2 & 5 & 5 & & \\
\hline F3 & 5 & 5 & & \\
\hline F1-A1 & 0 & 0 & 1 & 4 \\
\hline F1-A2 & 0 & 0 & 5 & 5 \\
\hline F1-A3 & 0 & 0 & 5 & 5 \\
\hline F3-A1 & 5 & 5 & 5 & 5 \\
\hline F3-A2 & 1 & 1 & 5 & 5 \\
\hline
\end{tabular}


Manuscript

\section{Figure captions:}

Figure 1. FESEM images of bare (a), ALD $\mathrm{Al}_{\mathrm{x}} \mathrm{Ta}_{\mathrm{y}} \mathrm{O}_{\mathrm{z}}$ mixture (A2) (b), FCAD Ta:O (F1) (c), FCAD Cr:O-Ta:O nanolaminate (F3) (d), FCAD Ta:O + ALD Al $\mathrm{Ta}_{\mathrm{y}} \mathrm{O}_{\mathrm{z}}$ mixture (F1-A2) (e) and FCAD Cr:O-Ta:O nanolaminate + $\mathrm{ALD} \mathrm{Al}_{\mathrm{x}} \mathrm{Ta}_{\mathrm{y}} \mathrm{O}_{\mathrm{z}}$ mixture (F3-A2) (f) coated steel.

Figure 2. TEM cross sectional images of duplex FCAD/ALD coated steel: FCAD $\mathrm{Ta}: \mathrm{O}+\mathrm{ALD} \mathrm{Al}_{\mathrm{x}} \mathrm{Ta}_{\mathrm{y}} \mathrm{O}_{\mathrm{z}}$ mixture (F1-A2) (a and b) and FCAD Cr:O-Ta:O nanolaminate $+\mathrm{ALD} \mathrm{Al}_{\mathrm{x}} \mathrm{Ta}_{\mathrm{y}} \mathrm{O}_{\mathrm{z}}$ mixture $(\mathrm{F} 3-\mathrm{A} 2)(\mathrm{c}$ and d).

Figure 3. ToF-SIMS depth profiles of duplex FCAD/ALD coated steel before and after immersion in $0.2 \mathrm{M} \mathrm{NaCl}$ solution at $\mathrm{pH}$ 2: (a and d) $\mathrm{Ta}: \mathrm{O}+\mathrm{Al}_{2} \mathrm{O}_{3}-\mathrm{Ta}_{2} \mathrm{O}_{5}$ nanolaminate (F1-A1), (b and e) $\mathrm{Ta}: \mathrm{O}+\mathrm{Al}_{\mathrm{x}} \mathrm{Ta}_{\mathrm{y}} \mathrm{O}_{\mathrm{z}}$ mixture (F1-A2) and (c and $\mathrm{f}$ ) $\mathrm{Ta}: \mathrm{O}+\mathrm{Al}_{\mathrm{x}} \mathrm{Ta}_{\mathrm{y}} \mathrm{O}_{\mathrm{z}}$ graded mixture (F1-A3).

Figure 4. Polarization results of single FCAD and duplex FCAD/ALD coated steel: (a) FCAD Ta:O (F1) and Cr:O-Ta:O nanolaminate (F3), (b) FCAD Ta:O + ALD $\mathrm{Al}_{2} \mathrm{O}_{3}-\mathrm{Ta}_{2} \mathrm{O}_{5}$ nanolaminate (F1-A1) / $\mathrm{Al}_{\mathrm{x}} \mathrm{Ta}_{\mathrm{y}} \mathrm{O}_{\mathrm{z}}$ mixture $(\mathrm{F} 1-\mathrm{A} 2) / \mathrm{Al}_{\mathrm{x}} \mathrm{Ta}_{\mathrm{y}} \mathrm{O}_{\mathrm{z}}$ graded mixture (F1-A3) and (c) FCAD Cr:O-Ta:O nanolaminate + ALD $\mathrm{Al}_{2} \mathrm{O}_{3}-\mathrm{Ta}_{2} \mathrm{O}_{5}$ nanolaminate (F3-A1) / $\mathrm{Al}_{\mathrm{x}} \mathrm{Ta}_{\mathrm{y}} \mathrm{O}_{\mathrm{z}}$ mixture (F3-A2) / $\mathrm{Al}_{\mathrm{x}} \mathrm{Ta}_{\mathrm{y}} \mathrm{O}_{\mathrm{z}}$ graded mixture (F3A3). The polarization curve of the uncoated steel is included in all images for reference.

Figure 5. ToF-SIMS $\mathrm{Cl}^{-}$depth profiles of duplex FDAD/ALD coated steel before and after immersion in $0.2 \mathrm{M} \mathrm{NaCl}$ solution at $\mathrm{pH}$ 2: (a) FCAD Ta:O $+\mathrm{ALD} \mathrm{Al}_{2} \mathrm{O}_{3}-\mathrm{Ta}_{2} \mathrm{O}_{5}$ nanolaminate (F1-A1), (b) FCAD Ta:O + $\mathrm{ALD} \mathrm{Al}_{\mathrm{x}} \mathrm{Ta}_{\mathrm{y}} \mathrm{O}_{\mathrm{z}}$ mixture (F1-A2) and (c) FCAD Ta:O + ALD $\mathrm{Al}_{\mathrm{x}} \mathrm{Ta}_{\mathrm{y}} \mathrm{O}_{\mathrm{z}}$ graded mixture (F1-A3).

Figure 6. EIS Bode plots of steel coated with duplex FCAD/ALD coatings during immersion in $0.2 \mathrm{M} \mathrm{NaCl}$ solution at $\mathrm{pH}$ 2: (a) FCAD Ta:O $+\mathrm{ALD} \mathrm{Al}_{2} \mathrm{O}_{3}-\mathrm{Ta}_{2} \mathrm{O}_{5}$ nanolaminate (F1-A1), (b) FCAD Ta:O + $\mathrm{ALD} \mathrm{Al} \mathrm{Ta}_{\mathrm{y}} \mathrm{O}_{\mathrm{z}}$ mixture (F1-A2) and (c) FCAD Ta:O + ALD Al Ta $_{\mathrm{y}} \mathrm{O}_{\mathrm{z}}$ graded mixture (F1-A3). 
Manuscript

Figure 7. EIS Nyquist plots of steel coated with duplex FCAD/ALD coatings during immersion in $0.2 \mathrm{M} \mathrm{NaCl}$ solution at $\mathrm{pH}$ 2: (a) FCAD Ta:O $+\mathrm{ALD} \mathrm{Al}_{2} \mathrm{O}_{3}-\mathrm{Ta}_{2} \mathrm{O}_{5}$ nanolaminate (F1-A1), (b) FCAD Ta:O + $\mathrm{ALD} \mathrm{Al}_{\mathrm{x}} \mathrm{Ta}_{\mathrm{y}} \mathrm{O}_{\mathrm{z}}$ mixture (F1-A2) and (c) FCAD Ta:O + ALD $\mathrm{Al}_{\mathrm{x}} \mathrm{Ta}_{\mathrm{y}} \mathrm{O}_{\mathrm{z}}$ graded mixture (F1-A3).

Figure 8. Equivalent circuit used for EIS data modelling. The symbols $R_{e}, R_{c t}$ and $R_{p i t}$ represent resistances of the electrolyte solution, the charge transfer and the pitting, respectively. The symbols $C P E_{c o a t}$ and $C P E_{d l}$ represent the constant phase elements of the coating and the double layer at the steel surface.

Figure 9. NSS results on steel protected with single FCAD and duplex FCAD/ALD coatings: FCAD Ta:O (F2), FCAD Cr:O-Ta:O nanolaminate (F3), FCAD Ta:O + ALD nanolaminate (F1-A1), FCAD Ta:O + ALD mixture (F1-A2), FCAD Ta:O + ALD graded mixture (F1-A3), FCAD Cr:O-Ta:O nanolaminate + ALD nanolaminate (F3-A1) and FCAD Cr:O-Ta:O nanolaminate + ALD mixture (F3-A2). 
Click here to download high resolution image
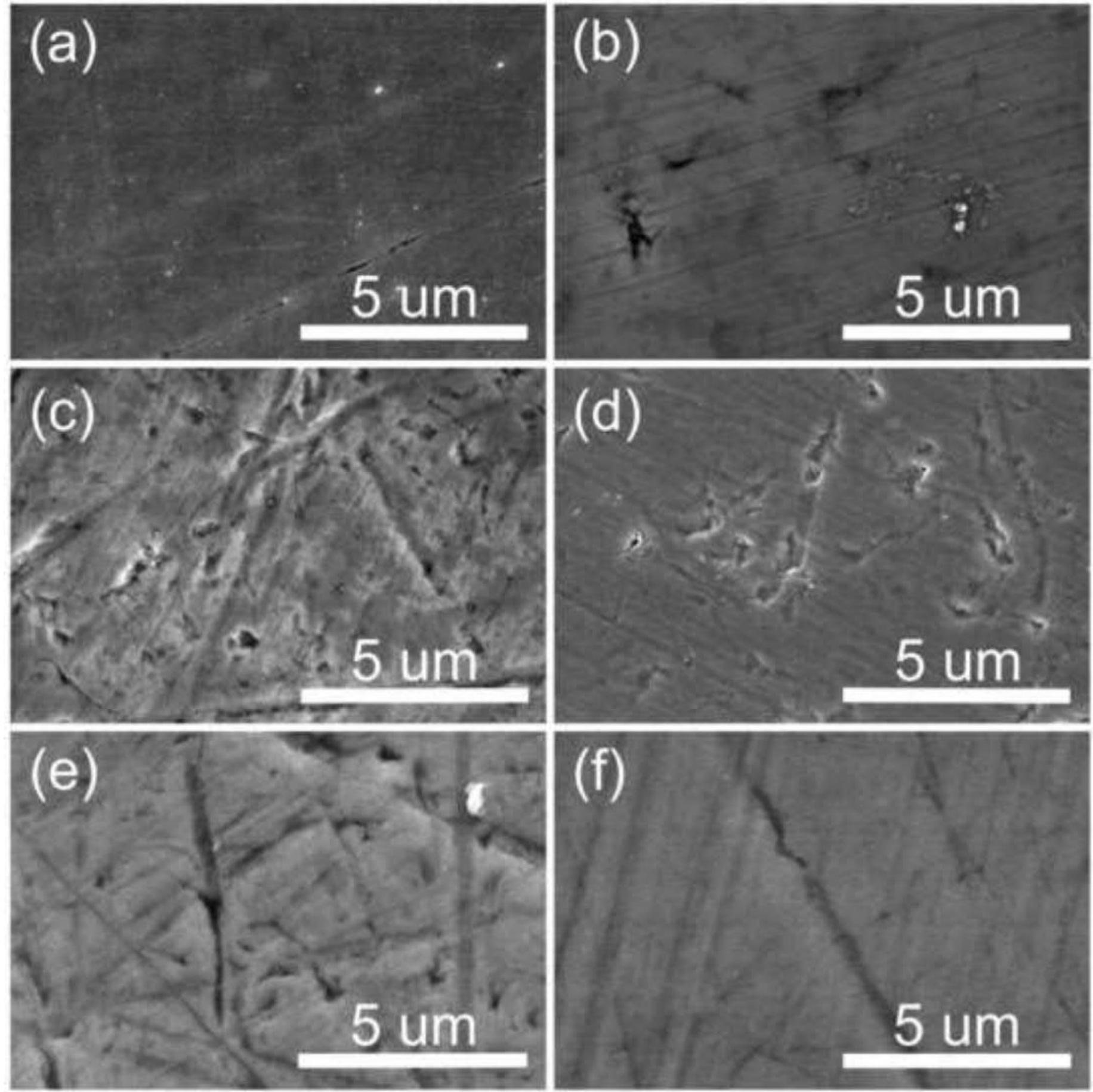

(f)

\section{5 um}



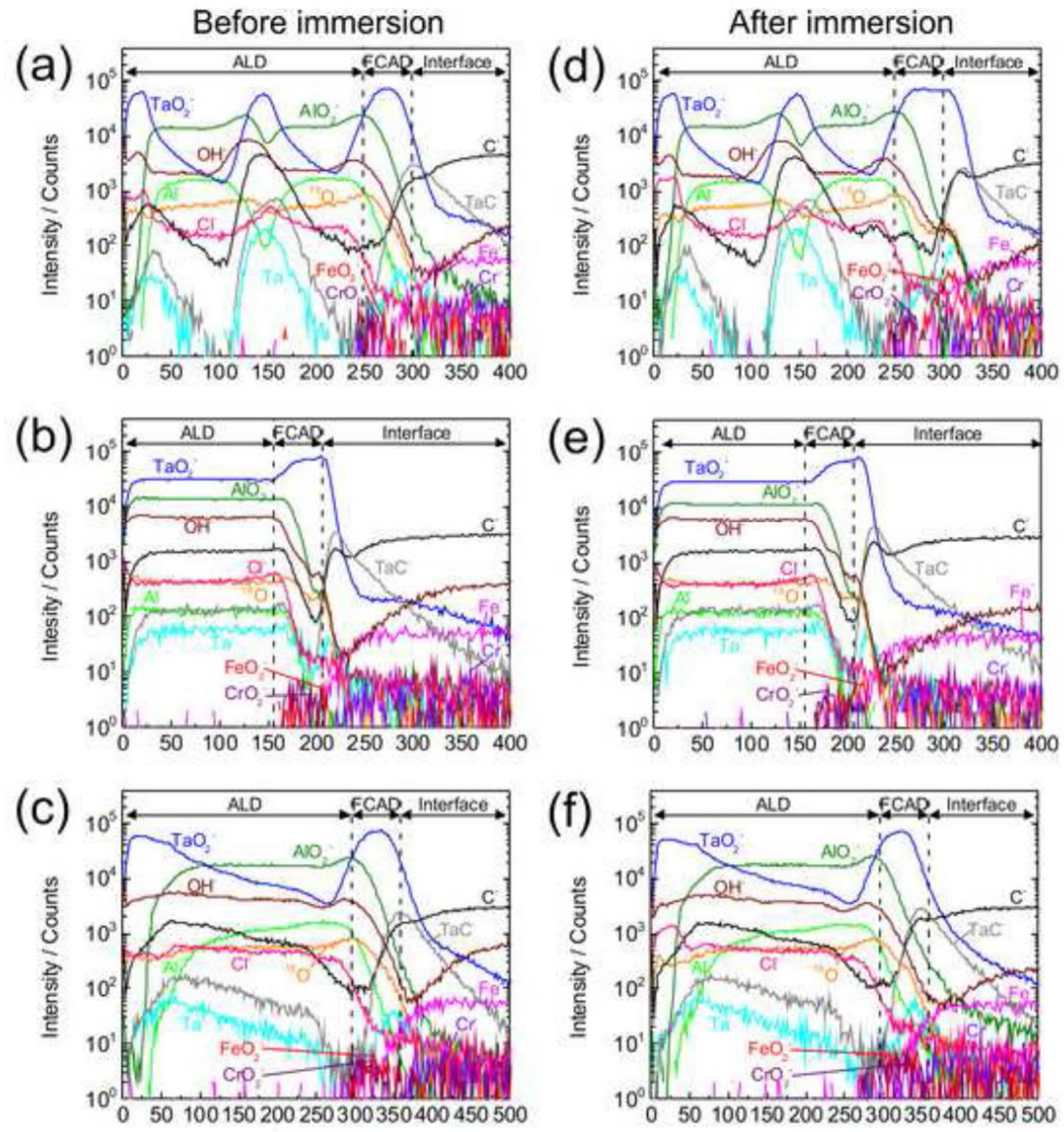

Time (s)

Time (s) 

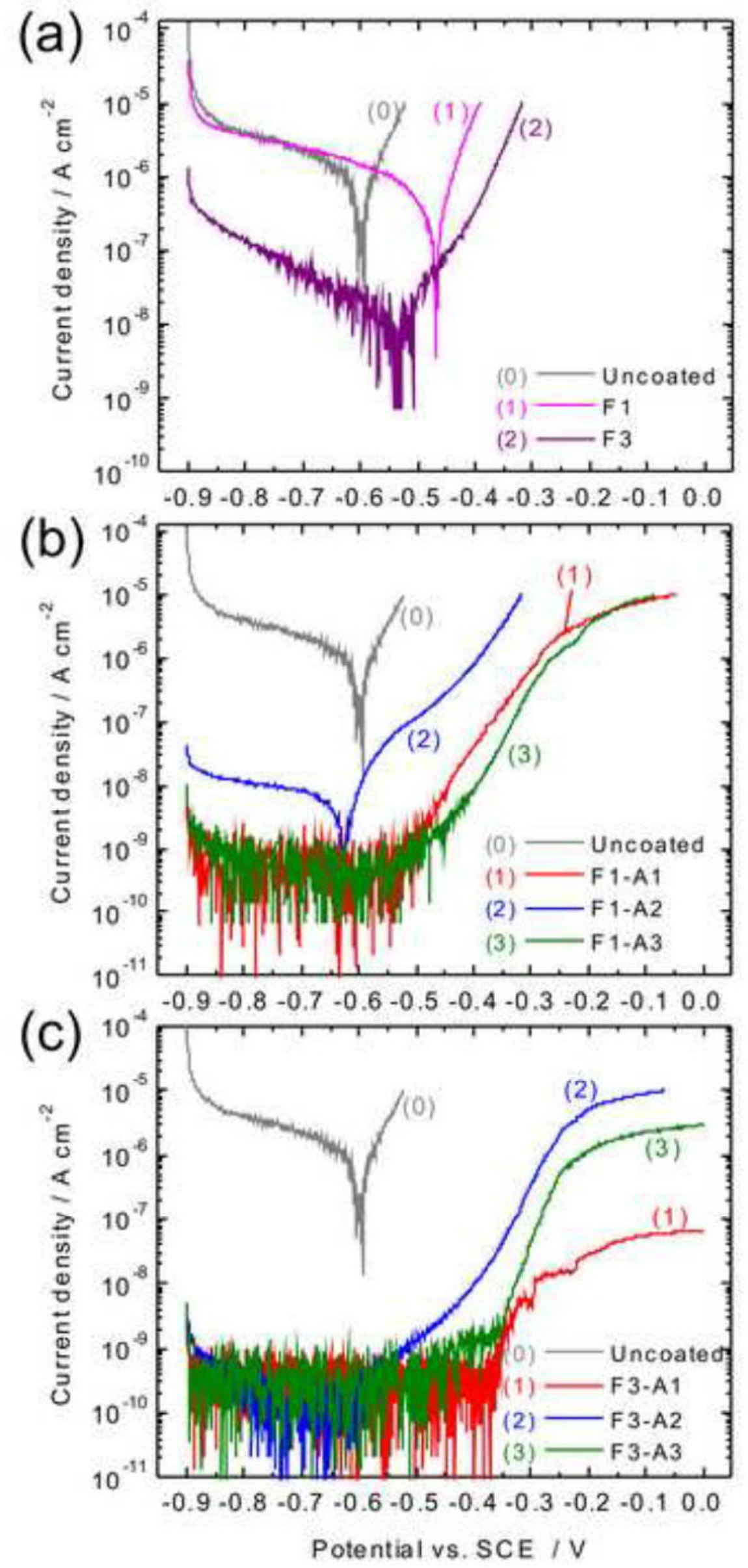

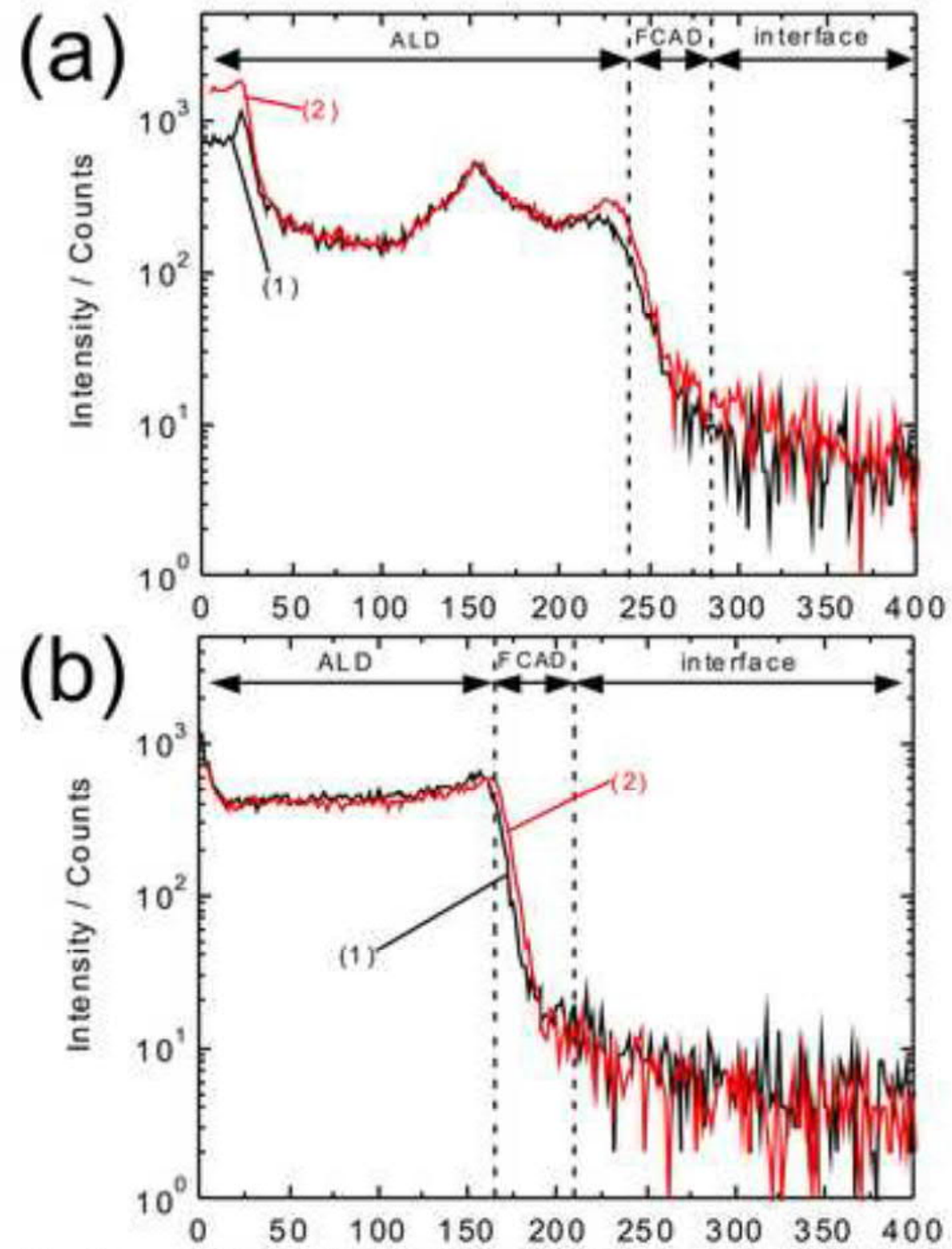

(c)

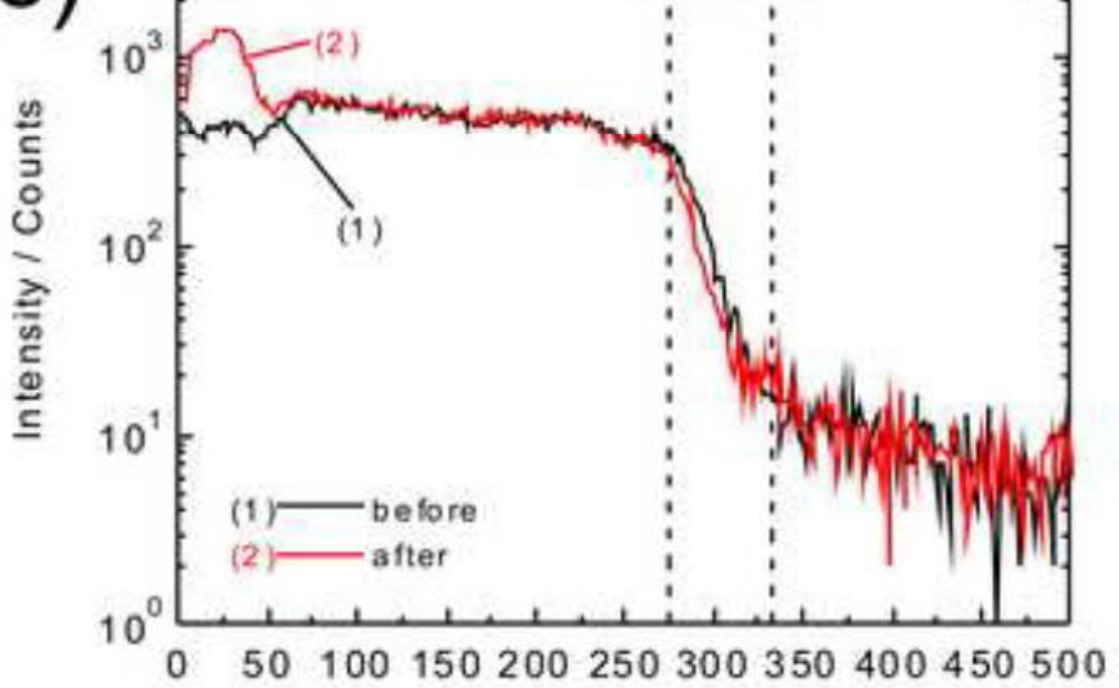

Sputtering Time/s 
Click here to download high resolution image
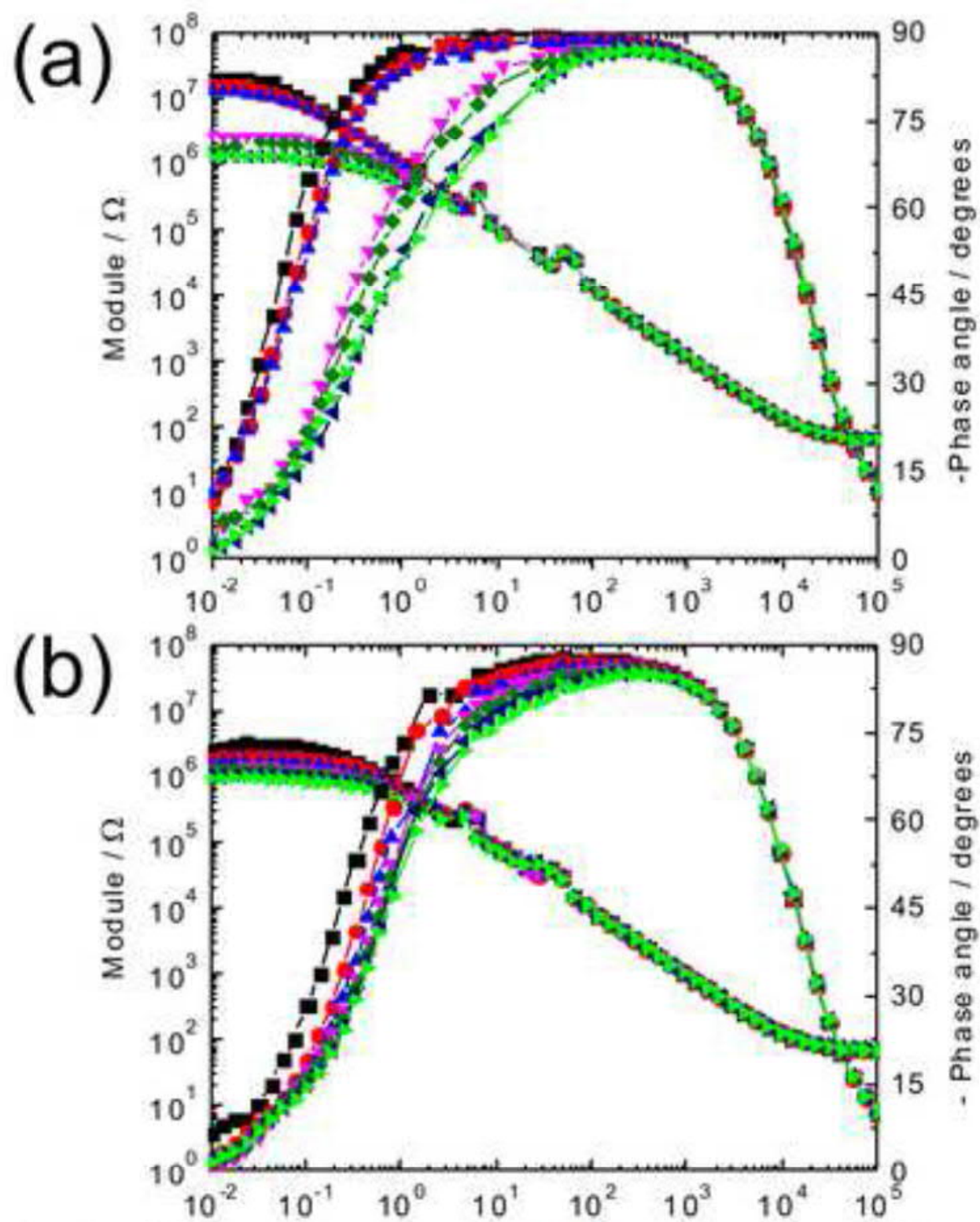

(c)
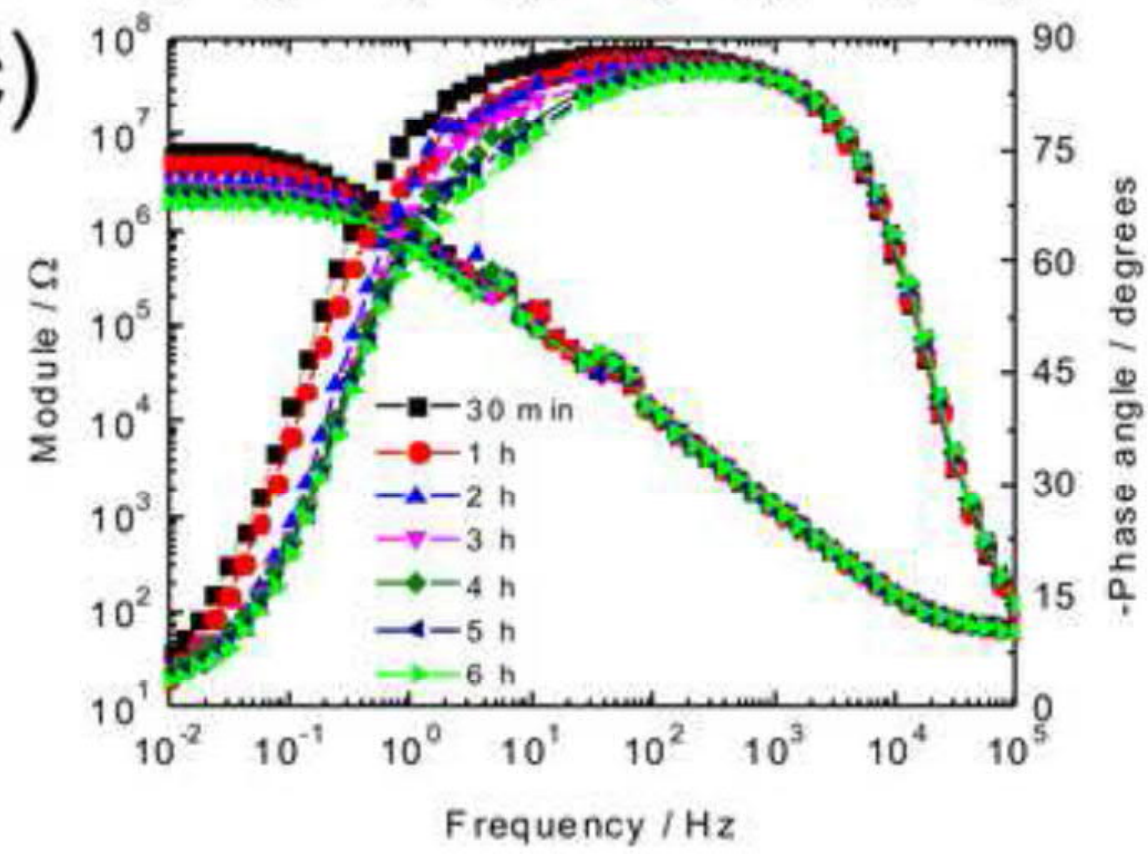

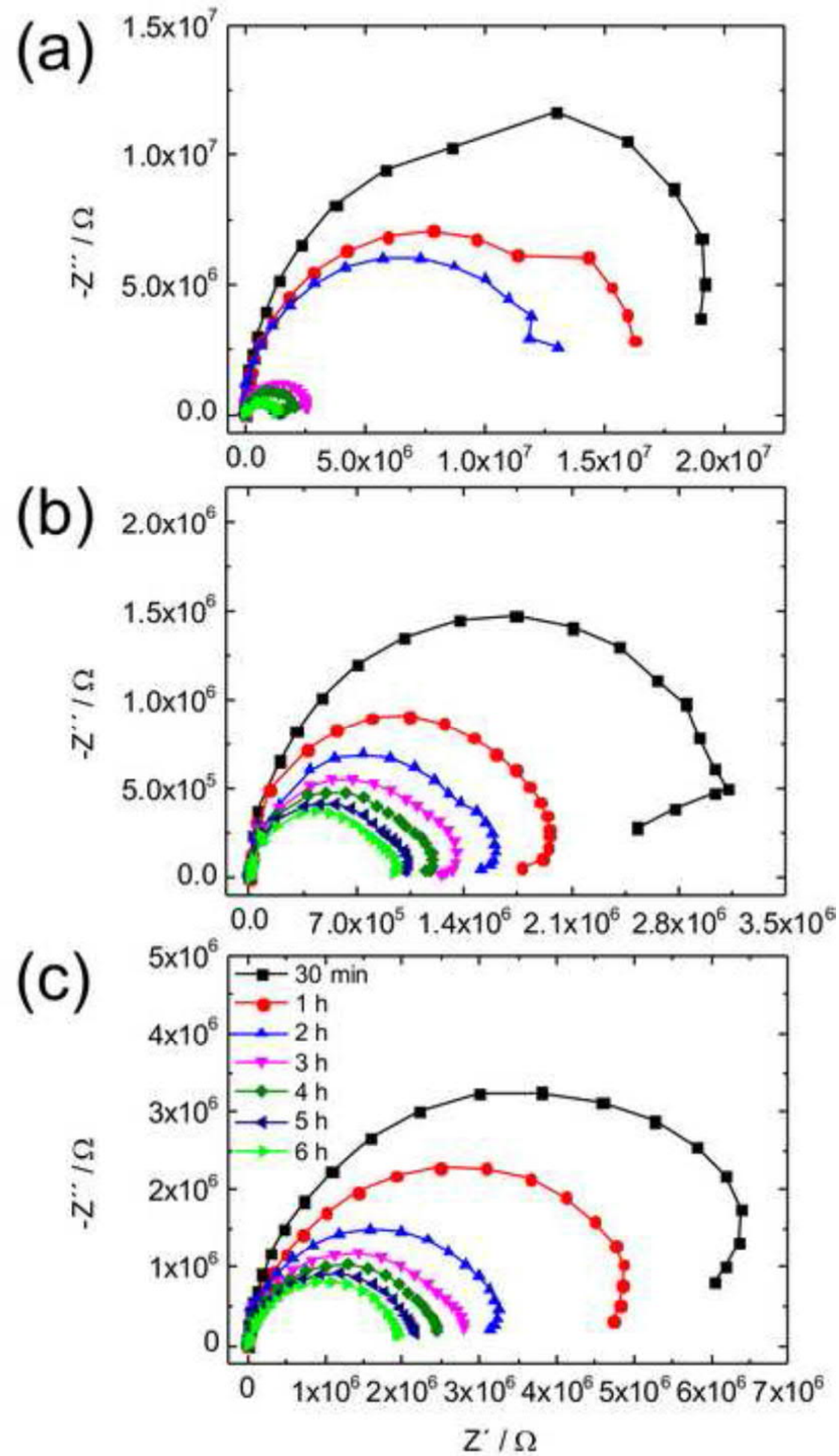


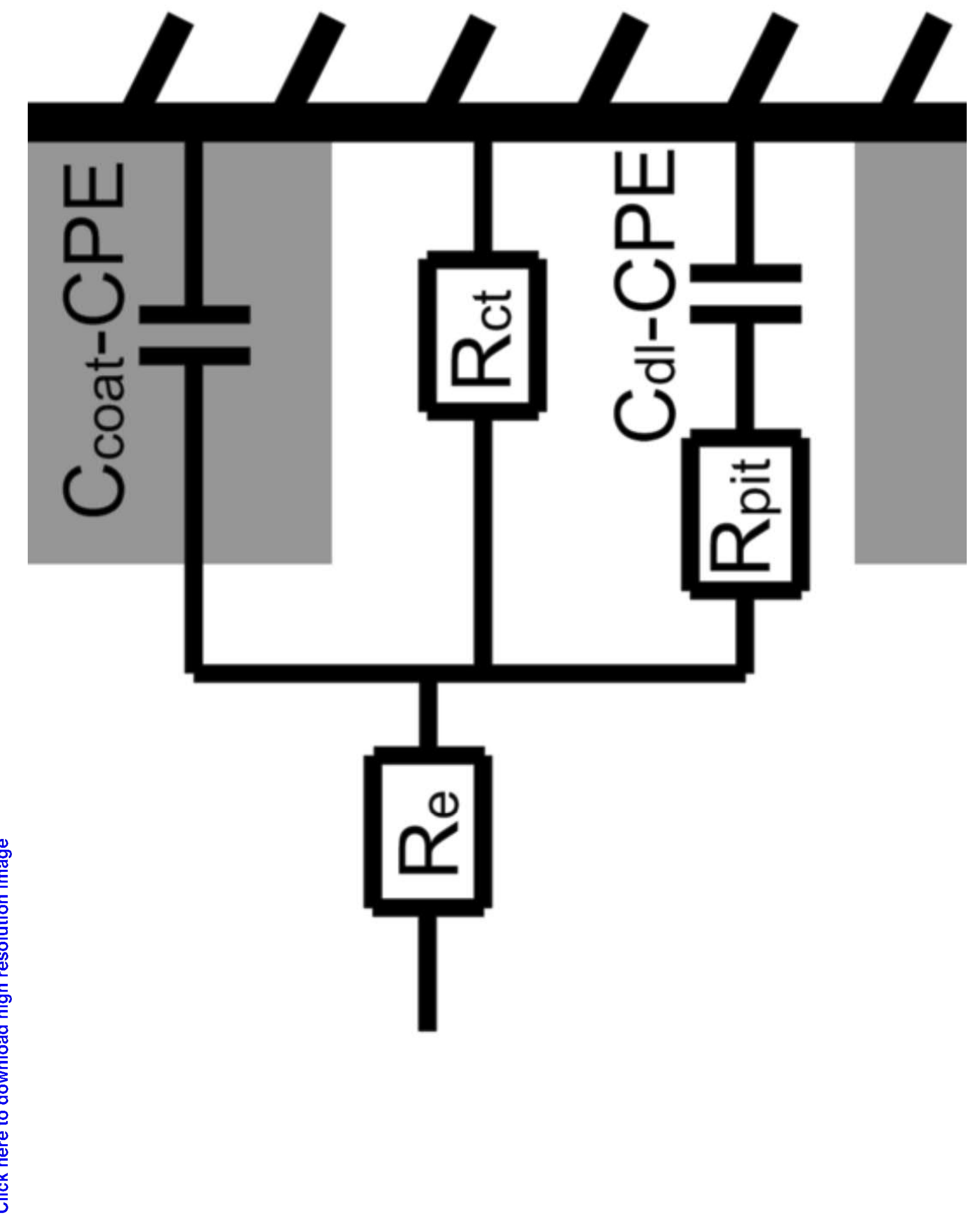


Code

\section{NSS}

Before After $2 \mathrm{~h} \quad$ After $4 \mathrm{~h}$ After $24 \mathrm{~h}$ After $48 \mathrm{~h}$

F2
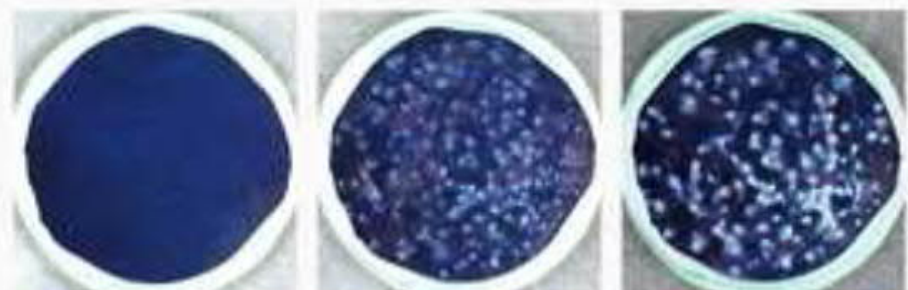

F3
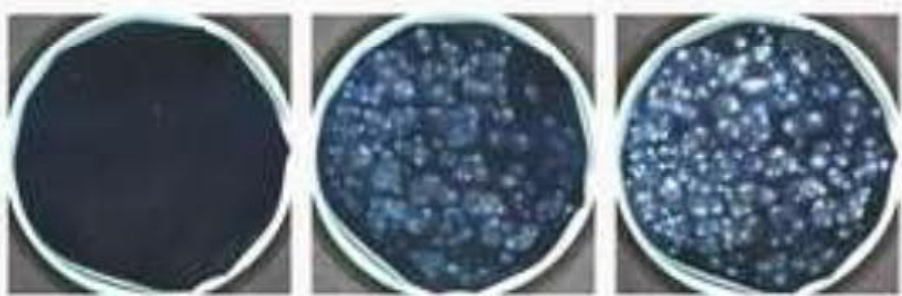

$\mathrm{F} 1-\mathrm{A} 1$
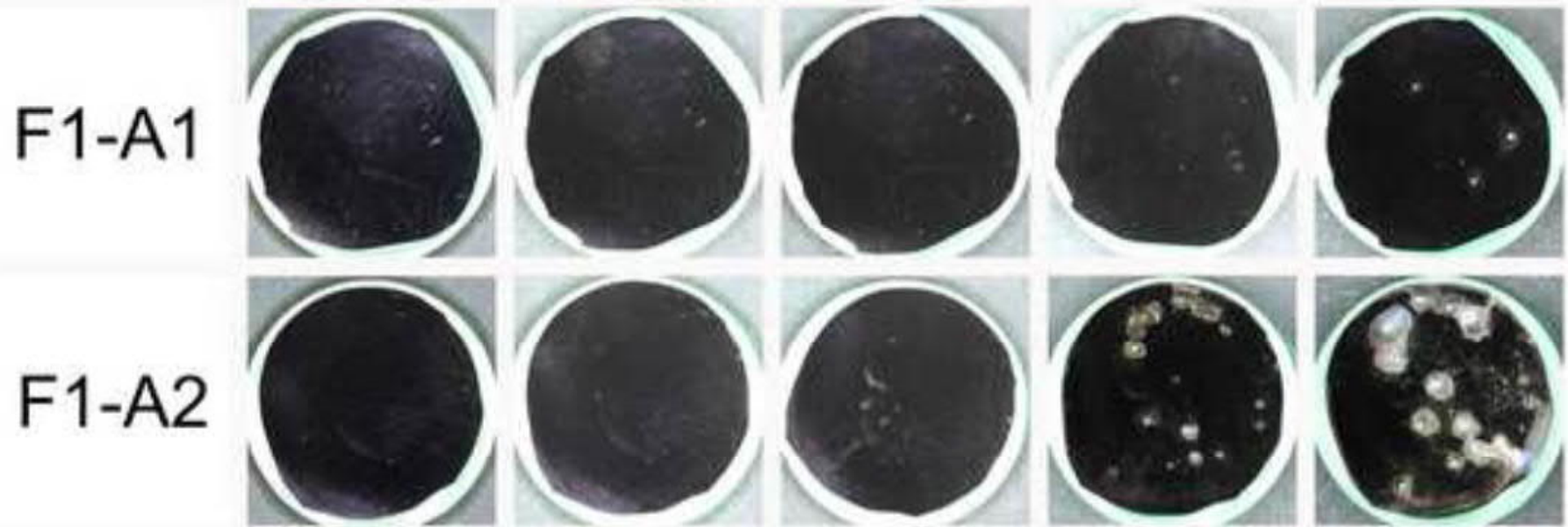

F1-A3
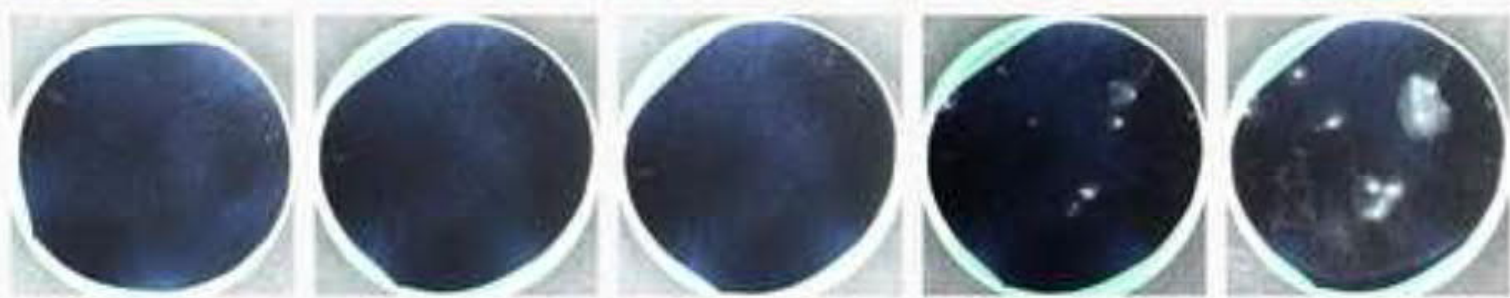

F3-A1
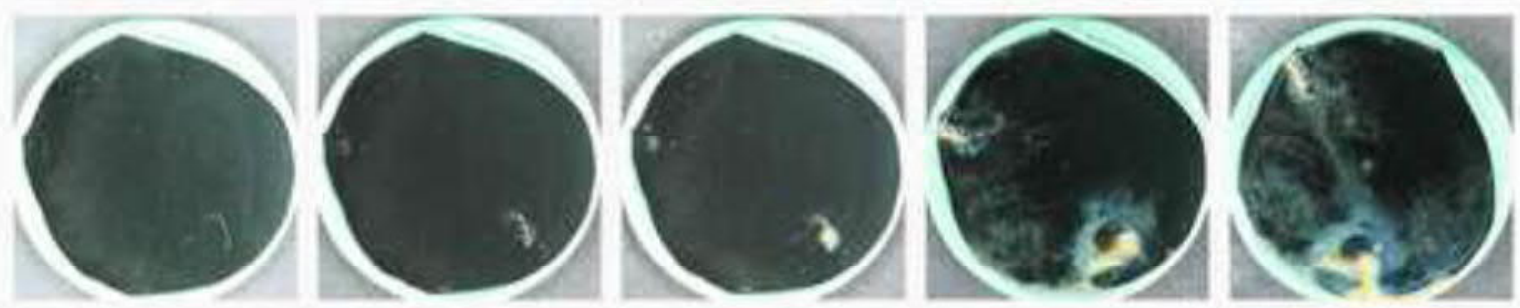

F3-A2
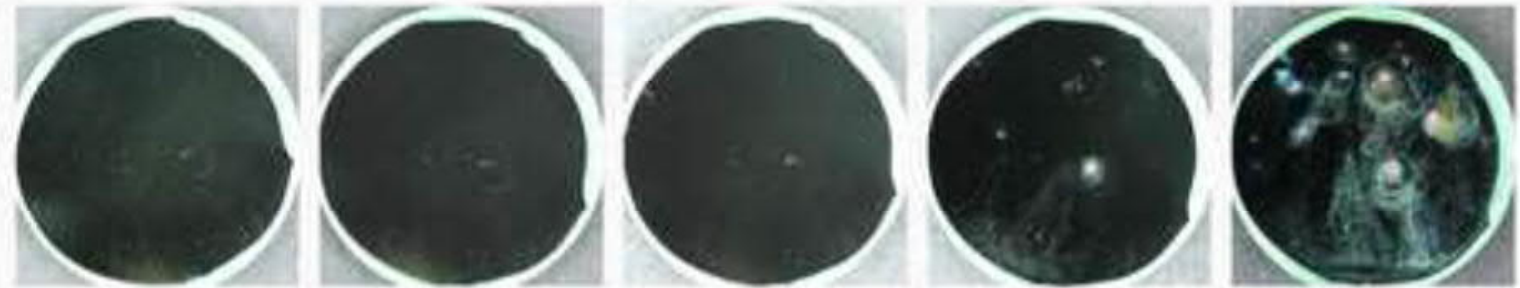